\title{
A moderate threonine deficiency affects gene expression profile, paracellular permeability and glucose absorption capacity in the ileum of piglets
}

\author{
Alice Hamard ${ }^{a, b}$, David Mazurais ${ }^{c}$, Gaëlle Boudry ${ }^{a, b}$, Isabelle Le Huërou-Luron ${ }^{a, b}$, Bernard Sève ${ }^{a, b}$ \\ and Nathalie Le Floc' $h^{a, b, *}$
}

\footnotetext{
a INRA, UMR1079, SENAH, F-35590 Saint-Gilles, France

${ }^{b}$ Agrocampus Rennes, UMR1079, F-35000 Rennes, France

c Ifremer, Département PFOM, centre de Brest, 29280 Brest, France

莡.

Part of the results was presented at the Xth International Symposium on Digestive Physiology in Pigs, May 2006, Vejle, Denmark. It was published as a short paper (Hamard A, Mazurais D, Boudry G, Le Huërou-Luron I Sève B, Le Floc'h, N. Physiological aspects and ileal gene expression profile of early-weaned piglets fed a low threonine diet. Livestock Science, 2007;108:17-19).
}

मै मे

Alice Hamard is funded by INRA and Région Bretagne grants.

*: Corresponding author : N. Le Floc'h, email address : nathalie.lefloch@rennes.inra.fr

\begin{abstract}
:
High dietary threonine extraction by the digestive tract suggests that threonine contributes to maintain gut physiology. In the present study, we evaluated the impact of a low (6.5 g of threonine/kg diet; LT group) or a control well-balanced threonine diet (9.3 $\mathrm{g}$ of threonine/kg diet; C group) given to piglets for 2 weeks on ileal permeability and $\mathrm{Na}+$-dependant glucose absorption capacity in Ussing chambers. The paracellular permeability was significantly increased in the ileum of LT compared to C piglets $(P=.017)$. The Na+-dependent glucose absorption capacity showed a nonsignificant increase in the LT piglets. In addition, we analysed ileal gene expression profiles in the LT and C groups using porcine multitissue cDNA microarrays. Compared to the $C$ piglets, the expression of 324 genes was significantly modified in the ileum of the LT piglets: 214 genes were overexpressed (145 annotated) and 110 were down-expressed (79 annotated). Among them, some are involved in immune and defense responses, energy metabolism and protein synthesis. Furthermore, microarray analysis highlights changes in the expression of the gene encoding for the sodium/glucose cotransporter (SGLT1) and of genes involved in the regulation of paracellular permeability (ZO-1, cingulin and myosin light chain kinase). In conclusion, our results indicate that a moderate threonine deficiency affects intestinal functionality.
\end{abstract}

Keywords: Threonine; Small intestine; Paracellular permeability; Gene expression 
52 Although small intestine represents less than 5\% of whole-body mass, it accounts for $25 \%$ of whole-body energy expenditure and for $20-50 \%$ of total protein turnover (7). This high metabolic activity generates important amino acid (AA) requirements. In order to meet its requirement, the small intestine extracts part of dietary AA $(40,41)$. Among essential AA, threonine is extracted in greater proportion by the small intestine $(28,41,43)$, suggesting that threonine is involved in intestinal functionality and maintenance. However, the metabolic fate and the functional role of threonine in the small intestine are still unclear.

The high rate of intestinal threonine extraction could be associated with protein synthesis (28) and especially to the synthesis of mucins $(17,27,45)$ which threonine content ranges from $13 \%$ to $26 \%$ of total AA $(29,30,37)$. Threonine deficiency could also impact on other functions of the small intestine. We previously demonstrated that feeding young piglets with a low threonine supply (70\% of recommendations), that corresponds to a moderate deficiency, for two weeks induced a villous atrophy associated with a reduction in aminopeptidase $\mathrm{N}$ activity in the ileum (20). Because villous atrophy is frequently associated with functional disturbances, further work was needed to determine the effect of threonine deficiency on small intestine physiology. The objective of the present study was to identify biological functions affected by a moderate threonine deficiency, which corresponds to a deficiency that remains within nutritional range. We focused on the distal part of the small intestine where we observed structural modifications. To do so, we evaluated the effect of the dietary content of threonine on ileal paracellular permeability and glucose absorption capacity in Ussing chambers. In addition, we used porcine cDNA microarrays to evaluate the impact of the dietary threonine 
considering the scarcity of knowledge about the implication of this AA in the physiology of the small intestine.

\section{Materials and Methods}

Animals and feeding. The experiment was conducted under the guidelines of the French Ministry of Agriculture for animal care. Seven pairs of Pietrain x (Large White x Landrace) piglets from the INRA experimental herd (Saint-Gilles, France) were weaned at 7 days of age. These pairs were constituted of littermates with close body weights $(2.5 \pm 0.06 \mathrm{~kg})$. From weaning, piglets were placed into individual stainless-steel cages in a room maintained at $30^{\circ} \mathrm{C}$.

Within each pair, one piglet received a control well-balanced diet (C group) and the other one a low threonine diet (LT group). The composition of the diets is presented in Table 1. Protein was supplied by skimmed-milk powder and a soluble fish protein concentrate. Those raw materials set the basal threonine content in both diets. A free AA mixture was added according to the recommendations of Chung and Baker (9) for weaned piglets. Free threonine was added only in the C diet. The nitrogen content of the LT diet was adjusted by addition of aspartic acid and ammonium citrate. Threonine content was $9.3 \mathrm{~g}$ per $\mathrm{kg}$ in the $\mathrm{C}$ diet and 6.5 g per kg in the LT diet. Diets provided $250 \mathrm{~g} / \mathrm{kg}$ of protein (Nx6.25) and 15 MJ of digestible energy (DE) per kg.

The meals were prepared as a mash (powdered diet-warm water, 2:1) just before distribution. The daily amount of diet was adjusted to the metabolic weight $(600 \mathrm{~kJ} / \mathrm{kg}$ body weight ${ }^{0.75}$ ) and given in four equal meals. The piglets were offered $50 \%$ of this daily intake the first two days. Water was offered ad libitum throughout the experiment. Piglets were weighed on experimental days 1, 4, 6, 8, 11, and 13 . 
Slaughter procedure. After two weeks of experiment and $3 \mathrm{~h}$ after the last meal, piglets were killed with a lethal dose of pentobarbital immediately followed by exsanguination. The gastrointestinal tract was quickly removed. The small intestine, from the Treitz ligament to

103 the ileo-caecal junction, was weighed empty of contents and the length was measured. It was 104 divided in three parts of equal length, the proximal jejunum, the distal jejunum and the ileum. 105 In the middle of each part, $3 \mathrm{~cm}$-segments were collected in phosphate-buffered formalin 106 (10\%, pH7.6) for morphometric measurements. A 20-cm segment of the ileum was sampled 107 108

Measurements of ileal glucose absorption capacity and paracellular permeability in Ussing chambers. Immediately after sampling, ileal segments were stripped of their seromuscular layers and mounted in Ussing chambers with an exposed area of $1.13 \mathrm{~cm}^{2}$. They were bathed on each side with a bicarbonate Ringer's solution with $16 \mathrm{mM}$ glucose and 16mM mannitol 124 on the serosal and mucosal sides, respectively and maintained at $38^{\circ} \mathrm{C}$ (6). The short-circuit 
current ( $\mathrm{I}_{\mathrm{SC}}$ ) and the transepithelial resistance were measured as already described (6). A first

126 set of Ussing chambers was used to estimate paracellular permeability through measuring the

127 flux of fluorescein isothiocyanate dextran 4000Da (FD4) as a model molecule. This molecule

128 was added on the mucosal side at the final concentration of $0.375 \mathrm{mg} / \mathrm{mL}$. Its transport was

129 monitored by sampling $500 \mu \mathrm{l}$ of bathing solution from the serosal side at 30 -min intervals for

130120 minutes. The solution was replaced by fresh medium to maintain a constant volume

131 within the chamber. The concentrations of FD4 in the serosal side were measured by

132 fluorometry. In a second set of Ussing chambers, $\mathrm{Na}^{+}$-dependent glucose absorption capacity

133 was evaluated. Increasing amounts of D-glucose were added to mucosal buffer every 5

134 minutes, resulting in final concentrations of 2, 4, 8, 16, and $32 \mathrm{mM}$. The addition of glucose

135 on the mucosal side was osmotically balanced by the addition of mannitol on the serosal side.

136 Maximal variation of the short-circuit current (Delta $\mathrm{I}_{\mathrm{SC}}$ ) was recorded at each concentration

137 and $\mathrm{V}_{\max }$ and $\mathrm{K}_{\mathrm{m}}$ for $\mathrm{Na}^{+}$-dependent glucose absorption were then calculated.

138

139 RNA extraction. Total RNA was extracted from ileal samples using Trizol reagent (Invitrogen

140 corporation, USA) according to manufacturer's instructions. Concentration of RNA was

141 quantified by measuring absorbance at $260 \mathrm{~nm}$ (Multiskan spectrum, Thermo Labsystems,

142 France) and RNA integrity was checked using Agilent 2100 bioanalyser (Agilent

143 technologies, Germany).

145 Microarray analysis and data processing. Transcriptomic analyses were performed on the 7

146 pairs of piglets using nylon microarrays obtained from the Resource Center GADIE (UMR

147 LREG, INRA, France) and encompassing 8960 clones from a multi-tissue porcine cDNA

148 library (AGENAE, INRA, France). The 8960 clones spotted on the arrays represented 8800 
genes, of which $60 \%$ are annotated. These arrays are recorded on the GEO Platform under the accession number GPL3729.

Labelling of cDNA complex probes, hybridization and washes were performed according to the procedures described by Mazurais et al. (31). Briefly, after their extraction from ileum samples, total purified RNA was retro-transcripted in the presence of $\left[\alpha-{ }^{33} \mathrm{P}\right] \mathrm{dCTP}$ for labelling. After array image acquisition (BAS 5000, Fuji), quantification of hybridization signals revealed the expression level of each 8960 clones (BZ Scan). Then, the expression level of each clone was first log-transformed to yield normal distribution and then mediancentred to minimize technical variability. We selected clones which displayed differential expression between $\mathrm{C}$ and LT groups using variance analysis $(\mathrm{P}<0.01$, GeneANOVA, CNRS, UPRESA 8087, France) (14). The selected clones were submitted to hierarchical clustering with the Gene Cluster software (16).

Real-time PCR. Reverse transcription was performed with $2 \mu \mathrm{g}$ of total DNAse-treated RNA (High capacity cDNA archive kit; Applied Biosystems, USA). The primers were designed using Primer Express Software (Applied Biosystems, USA) based on sus scrofa published nucleotides sequences (Iccare) and are described in Table 2. Real-time PCR was carried out on an ABI PRISM 7000 SDS thermal cycler (Applied Biosystem, USA). Real-time PCR was performed in $25 \mu \mathrm{L}$ of PCR buffer (SYBRGreenTM PCR Master Mix, Applied Biosystems, USA) with $500 \mathrm{nM}$ of each primer, $5 \mu \mathrm{l}$ of optimized concentration of the RT reaction and $2 \mathrm{U}$ of Uracyl DNA Glycosylase (Invitrogen, France). Forty cycles of PCR consisting of denaturation at $95^{\circ} \mathrm{C}$ for $15 \mathrm{sec}$ and annealing and extension at $60^{\circ} \mathrm{C}$ for $1 \mathrm{~min}$ were performed. Amplification product specificity was checked by dissociation curve analyses. To determine the efficiency of each primer set, a standard curve was done with serial dilutions of a pool of samples' RT products. Then for each sample, the amount of the target RNA was 
174 determined by comparison with the corresponding standard curve (3). Finally the amount of

175 the target RNA was calculated relative to the GAPDH transcript level of the same sample.

176

177 Statistical analysis. For all measurements, except for transcriptomic analysis (see Microarray

178 analysis and data processing), analysis of variance was performed using General Linear

179 Model procedure of Statistical Analysis System (SAS Institute, Cary, NC, USA). The effects

180 of pair (litter) and dietary threonine supply were tested using the residual variation between

181 piglets as the error. All the results are presented as Least square means (LSmeans) \pm sem.

182 Differences were considered significant when $\mathrm{p}<0.05$. Trends $(0.1<\mathrm{p}<0.05)$ were

183 presented for discussion.

184

\section{Results}

186 A moderate threonine deficiency did not affect growth rate. As expected the average feed intakes were not significantly different between pair-fed C and LT piglets (Table 3). Threonine intake was significantly reduced by $29 \%$ in the LT piglets compared to the C

189 piglets $(\mathrm{p}<0.0001)$. The low threonine supply affected neither final body weight, nor body 190 weight gain.

191

A moderate threonine deficiency induced ileal villous hypotrophy. The weight and length of the small intestine were not altered by the low threonine supply (data not shown). In the

194 proximal and distal jejunum, no modification of the mucosa morphology was observed (Table

195 4). In the ileum, villous height tended to be reduced in $L T$ piglets compared to $\mathrm{C}$ piglets $(\mathrm{p}=$ 196 0.06). In accordance with this result, villous surface was reduced by $18 \%$ in LT piglets compared to C piglets $(\mathrm{p}<0.01)$. 
A moderate threonine deficiency increased glucose absorption capacity. Measurements

200 performed in Ussing chambers showed a trend to an increased $\mathrm{Na}+$-dependent glucose absorption capacity, measured as the delta $\mathrm{I}_{\mathrm{SC}}$ to graded glucose addition, in LT piglets as illustrated by a higher dose-response curve (Figure 1): $\mathrm{V}_{\max }$ tended to increase by $81 \%$ in the ileum of LT piglets compared to C piglets ( $p=0.1$; Table 5), and $\mathrm{K}_{\mathrm{m}}$ did not change between

204 LT and C groups.

205

A moderate threonine deficiency modified epithelial barrier function. The paracellular permeability measured in Ussing chambers was 89\% increased in the ileum of LT piglets compared to $\mathrm{C}$ piglets ( $\mathrm{p}=0.017$; Figure 2). Moreover, despite no statistical significance, the reduced threonine supply decreased transepithelial resistance by 30\% (Figure 3).

A moderate threonine deficiency affected ileal transcriptome. A 30\% reduction of dietary threonine supply significantly affected the expression of 324 genes $(p<0.01)$ : 214 genes were over expressed (145 annotated) and 110 were down expressed (79 annotated) in LT piglets.

214 Differentially expressed genes are listed in Supplemental Tables 1 and 2. The fold changes of 215 down expressed genes in LT piglets ranged between 0.42 and 0.78 . For over expressed genes, 216 they ranged between 1.51 and 3.00 except for SGLT-1 which expression was 4.9-fold 217 increased in LT group.

218 Differentially expressed genes were classified according to their biological process ontology 219 determined from Uniprot/Swiss-Prot database and the QuickGO Gene Ontology browser 220 (http://www.ebi.ac.uk/ego/). Some genes were not classified in a functional group and for some others no informative annotation was available (Supplemental Tables 1 and 2). 
224 (C1S), the MHC class I antigen (HLA-B), the T-cell differentiation antigen CD6 (CD6), the 225 C-C motif chemokine 16 (CCL16) and chemokine receptors (IL17RB, CCR4, DARC). We 226 also noted the overexpression of genes coding the selenoprotein W (SEPW1), the beta227 defensin 129 (DEFB129), the microsomal glutathione S-transferase 1 (MGST1) and the 228 mucin 1 (MUC1), these proteins playing a crucial role in antimicrobial or antioxidative 229 defenses.

$230 \quad$ Feeding a low threonine diet also affected the expression of genes involved in cell turnover. The gene encoding IGF2 was overexpressed whereas several genes acting as inhibitor of cell proliferation (BTG1 protein, BTG1; Pin2-interacting protein X1, PINX1; Forkhead box protein C1, FOXC1) were downexpressed in the ileum of LT piglets. The expression of two genes involved in the induction of apoptosis, the BH3 interacting domain death agonist (BID) and the death-associated protein kinase 1 (DAPK1), was increased. (SLC24A4), the phospholemnan (PXYD1), the amiloride-sensitive sodium channel betasubunit (SCNN1B) as well the $\mathrm{Y}+\mathrm{L}$ amino acid transporter 1 (SLC7A7) and the 239 sodium/glucose cotransporter 1 (SGLT-1) was significantly increased in the ileum of LT 240 piglets. The increase in SGLT-1 mRNA expression was confirmed by RT-PCR (2.04-fold, P $241<0.05)$ (Figure 4). This could indicate modifications in the transport of ions and nutrients. 242 Modifications in the expression of genes involved in the intracellular protein transport were 243 also observed. For example, genes encoding the kinectin (KTN1), the centractin (ACTR1B), 244 the transmembrane protein 9 precursor (TMEM9), the Golgin subfamily A member 5 245 (GOLGA5), the importin alpha-1 subunit (KPNA1) were overexpressed whereas genes 246 coding the adapter-related protein complex 3 delta 1 subunit (AP3D1), the charged 247 multivesicular body protein 1a (PCOLN3), the vacuolar protein sorting-associated protein 
33B (VPS33B) or the kinesin-like protein KIF2 (KIF2A) were downexpressed in the ileum of

249 LT piglets.

Piglets fed the LT diet exhibited increased ileal expression of genes involved in cell adhesion (tight junction protein ZO-1, TJP1; cingulin, CGN; paxillin, PXN; cadherin EGF LAG seven-pass G-type receptor 2, CELSR2; plectin 1, PLEC1; collagen alpha 1, CO9A1; integrin $\alpha 5$, ITGA5) and communication (ephrin A-4, EFNA4; gap junction $\beta 5$, GJB5) as well as in cytoskeleton organisation (neurofilament triplet $M$ protein, NEFM; tropomodulin, 255 TMOD1; tropomyosin 1, TPM1; Wiskott-Aldrich syndrome protein interacting protein homolog, WASIP). The significant increase in the expression of ZO-1 and cingulin (CGN) was confirmed by RT-PCR analysis: the relative levels of ZO-1 and CGN mRNA were 26\% and 36\% higher in LT piglets (Figure 4) although differences did not reach significance. Lack of significance could be explained by a high variability.

LT piglets displayed also modifications in the expression of genes involved in transcriptional and translational processes of protein synthesis. For example, genes coding the DNA directed RNA polymerase II $140 \mathrm{kDa}$ polypeptide (POLR2B), the RNA polymerase263 associated protein 1 (PAF1), the transcription initiation factor IIE alpha subunit (GTF2E1), 264 and the transcription initiation factor IIB (GTF2B) were overexpressed. On the contrary, the 265 eukaryotic translation initiation factor 2-alpha kinase 4 (GCN2), known to inactivate eIF2, 266 and the eukaryotic translation initiation factor 4A-binding protein 1 (EIF4EBP1), known to 267 inactivate eIF4, were downexpressed. The expression profile of these genes could be 268 indicative of an increase in protein synthesis rate. The LT diet also induced modifications of 269 transcription factors regulating expression of specific target genes (KLF9, ZNF644, ZNF169, 270 ZFP161, ZFP37, ZNF429). Most of genes involved in mRNA splicing were downregulated 271 (PRMT5, RBM9, SF1, SFRS5, SRRM1, STRAP, LSM2). Genes involved in RNA 
metabolism such as mRNA stability (SERBP1) or mRNA degradation (EDC3) were also differentially expressed in the ileum of LT piglets.

The LT diet altered the ileal expression of genes involved in the cellular protein metabolism. Apart from genes involved in regulation of translation (noticed above), we identified genes involved in protein folding (Dnaj homolog subfamily B member 9, DNJB9; peptidyl-prolyl cis-trans isomerase, PPIF; prefoldin subunit 2, PFDN2; torsin A, TOR1A) and protein catabolism (STIP1 homolog and U box-containing protein 1, STUB1; mitochondrial processing peptidase beta subunit, MPPB; F-box/wd-repeat protein 4, FBXW4; CAAX prenyl protease 1 homolog, ZMPSTE24; ubiquitin carboxyl-terminal hydrolase BAP1, BAP1; proteasome subunit beta type 3, PSMB3; probable E3 ubiquitin-protein ligase TRIP12, ubiquilin, UBQLN1...). Nevertheless, the expression profile of these genes did not allow us to conclude about the impact of the LT diet on these biological processes.

Finally, we also showed differential expression of genes involved in fatty acid metabolic process (carnitine O-acetyl transferase, CACP; carnitine O-palmitoyltransferase I, CPT1B, peroxisomal-coenzyme A synthase, FAT2; peroxisomal 3,2-trans-enoyl-coenzyme A isomerase, PECI; fatty acid-binding protein, epidermal, FABP5; dihydroxyacetone phosphate acyltransferase, GNPAT), in generation of energy (ATP synthase O subunit, ATP5O; NADHubiquinone oxidoreductase 13kDa-B subunit, NDUFA5) or in signal transduction (calcitonin receptor precursor, CALCR; GTPase-activating protein GAP, GAP; calcium/calmodulindependent protein kinase type II beta chain, CAMK2B; insulin receptor substrate 1, IRS1; phosphatidylinositol 4-kinase alpha, PIK4CA; phosphatidylinositol-4phosphate 5-kinase type I gamma, PIP5K1C; tyrosine-protein kinase JAK1, mitogen-activated protein kinase 8, JNK1...).

\section{Discussion}


As previously shown, a low threonine supply induced ileal villous hypotrophy (20). It was

298 associated with alterations of functionality. Indeed, a novel finding of the present study is that 299 a 30\% reduced threonine supply induced increased ileal paracellular permeability as measured 300 by the mucosa-serosa FD4 flux. Such an increase was previously reported in piglets 301 encountering non optimal nutritional conditions, receiving total parenteral nutrition (24), 302 submitted to $48 \mathrm{~h}$ fasting (8) or in response to undernutrition associated with weaning (5).

303 Increased paracellular permeability reflects a reduction in epithelial barrier selectivity 304 and consequently a greater susceptibility to antigens passage across the intestinal epithelium 305 even if not associated with clinical signs (19). Piglets fed the LT diet presented neither 306 diarrhea nor feverish episode. They consumed all their feed and their weight gain was not 307 affected. The good sanitary and nutritional conditions have probably minimized the incidence 308 of gut permeability and morphology modifications. Analyses perfomed with cDNA 309 microarrays showed that genes coding the complement C1s subcomponent (C1S), the MHC 310 class I antigen (HLA-B), the T-cell differentiation antigen CD6 (CD6), the C-C motif 311 chemokine 16 (CCL16) or chemokines receptors (IL17RB, CCR4, DARC) were 312 overexpressed in the ileum of LT piglets. This might reflect immune response to the passage 313 of antigens through the intestinal epithelium. For example, the overexpression of genes 314 coding chemokines and chemokine receptors characterises an inflammatory state (1). CCL16 315 is known to be a powerful proinflammatory chemokine that is expressed in ulcerative colitis 316 (36). Moreover, feeding the LT diet induced increased expression of genes encoded for 317 mucins, S-glutathione-transferase 1, the selenoprotein $\mathrm{W}$ or a defensin. These proteins play a 318 crucial role in intestinal protection $(18,35,46)$. Overexpression of MUC1 mRNA is of 319 particular interest because threonine utilisation by the gut is generally associated with mucins 320 synthesis (MUC2 and MUC3 were not represented on our microarrays). Mucins production is 321 increased during infection (13) or inadequate nutritional conditions (33). 
Microarray analysis revealed transcriptional modifications of factors controlling the

323 paracellular permeability (ZO1, cingulin and MLCK). Changes in the expression of these genes are expected to be associated with decreased paracellular permeability in the ileum of LT piglets, which is apparently inconsistent with the physiological data we obtained with Ussing chambers. Indeed, genes encoded for ZO1 and cingulin were up expressed in LT piglets. Cingulin and ZO1 are important components of the tight junction which is the major element of the paracellular pathway. These two proteins belong to the complex structure coupling the transmembrane sealing protein (occludin and claudins) and the actin network (32). They play a pivotal role in the structural and functional organization of the tight junction. Impaired intestinal permeability has been associated with lower expression of ZO-1 in pathophysiological conditions $(34,38,39)$. The role of cingulin in the regulation of paracellular permeability remains to be confirmed. Myosin light chain kinase (MLCK) allows the phosphorylation and the contraction of the perijunctional actomyosin ring leading to increased paracellular permeability (42). We hypothesized that cingulin and ZO1 over expression and MLCK down expression observed in the ileum of LT piglets could indicate an attempt to restore barrier function in response to functional changes.

Restoration of barrier function implied different processes such as cell proliferation and migration (4). Integrins play a crucial role in these processes. In our experiment, several genes encoding for actors of the integrin signalling pathway (PAK4, MLCK and WIP, integrin $\alpha 5$, paxillin) were differentially expressed in the ileum of LT piglets compared to C piglets. The gene coding the integrin $\alpha 5$ was overexpressed in the ileum of LT piglets. The increase in mRNA expression of integrin $\alpha 5$ promotes cell adhesion to fibronectin and cell migration in various cell types $(10,11,22,44)$. In the intestine, the role of integrin $\alpha 5$ in cell proliferation, notably during repetitive deformation $(26,47)$ has been explored. The fixation between the integrin and extracellular matrix proteins leads to the recruitment of proteins such 
as the paxillin to the cellular membrane and the subsequent activation of p21-activated

kinases such as PAKs involved in cytoskeletal rearrangement (23). Genes coding the paxillin and the PAK4 isoform were overexpressed in the ileum of LT piglets. Finally the gene coding the WIP, an important actin-binding protein that participates in the deformation of the actin network for migration (2) was overexpressed. Overall, the expression profile of these genes may prefigure the activation of the integrin pathway and supports the hypothesis of barrier restoration.

The over expression of SGLT-1 gene associated with the increased glucose absorption capacity measured in Ussing chambers demonstrated that threonine deficiency stimulated glucose absorption via an increase of SGLT-1 transporter. Indeed, the lack of an effect on the $\mathrm{Km}$ indicated no change in the affinity of the transporter for its substrate. The trend for an increase in $\mathrm{V}_{\max }$ could be due to either an increase in SGLT-1 activity and/or an increase in $\mathrm{Na}^{+}-\mathrm{K}^{+}$-ATPase activity. An increase in glucose absorption has already been observed in other situations such as a 48h fasting (8) or undernutrition associated with weaning (5). Glucose is a major source of energy for body tissues and notably for the small intestine (15).

362 So we hypothesized that an increase in glucose absorption capacity reflects an increase energy 363 demand in the small intestine, or peripheral tissues, or both in LT piglets. Supporting our 364 hypothesis two genes involved in energy generation were also differentially expressed: the 365 gene coding the ATP synthase O subunit, a component of the mitochondrial proton366 translocating ATP synthase complex and the gene coding the NADH-ubuquinone 367 oxidoreductase $13 \mathrm{kDa}-\mathrm{B}$ subunit from the mitochondrial respiratory chain complex I. 368 Additionally or otherwise, it appears that the contribution of glucose to intestinal energy 369 production depends on age. Darcy-Vrillon et al. (12) showed that the capacity of cultured porcine enterocytes to use glucose was high during the first week of life and decreased the 
second week when the small intestine used mainly AA. Therefore that change in energy supplier may have been delayed in LT piglets.

We showed that a low threonine supply induced structural and functional alterations. These modifications could result from an alteration in protein synthesis rate. In accordance with this hypothesis, Wang et al. (45) demonstrated that protein synthesis rate was reduced in the small intestine of piglets receiving less than $50 \%$ of daily threonine recommendations. Our results did not confirm this observation since intestinal protein synthesis rate was not altered by a 30\% reduced threonine supply (21). Using transcriptomic analysis, we identified genes coding regulatory factors of protein synthesis that were differentially expressed in the ileum of LT piglets. The downregulation of genes coding the eukaryotic translation initiation factor 2-alpha kinase 4 (GCN2) and the eukaryotic translation initiation factor 4E binding protein 1 (4E-BP1) is of particular interest. These genes are implicated in the down regulation of mRNA translation. Firstly, GCN2 prevents the formation of the 43S pre-initiation complex (Met-tRNA, GTP and eIF2) by phosphorylating the translation initiation factor eIF2 $\alpha$. Secondly, 4E-BP1 inhibits the assembly of the eIF4E-mRNA complex to the 40S ribosomal subunit by binding to the eukaryotic initiation factor 4E (eIF4E). These two factors are assumed to be implicated in the downregulation of protein synthesis by AA starvation. For example, in vitro leucine deprivation induced activation of these factors and consequently inhibition of the initiation phase of mRNA translation (25). In our study, the down regulation of these genes was expected to be associated with an increase or an attempt to increase protein synthesis rate. Regarding the lack of effect on fractional synthesis rate (21), we hypothesized that the downexpression of GCN2 and 4E-BP1 in the ileum of pigs fed the LT diet could be a mechanism for preserving protein synthesis in condition of moderate threonine deficiency.

In conclusion, this study demonstrates for the first time that a $30 \%$ reduced threonine supply for two weeks induced increased paracellular permeability and glucose absorption 
capacity. Moreover transcriptomic analysis showed that a moderate threonine deficiency 397 altered ileal gene expression profiles. These transcriptional modifications opened new 398 pathways of investigation. Notably, the increase in the expression of genes involved in 399 immune and defence functions associated with the increased paracellular permeability suggest 400 that threonine may be essential to preserve intestinal integrity. Therefore the response of the 401 piglets to a reduced threonine supply should be evaluated in aggression situations in order to 402 provide irrefutable evidence for a protective role of this amino acid on a stressed intestine.

403

404 Acknowledgments

405 We would like to thank the GADIE Center (UMR314, LREG INRA-CEA, Jouy-en-Josas

406 Cedex, France) for producing the porcine microarray. We also thank Veronique Romé, Cécile

407 Perrier and Romain d'Inca for technical assistance, and Yves Lebreton, Francis Legouevec 408 and Vincent Piedvache for animal care.

409

410 


\section{References:}

1. Ajuebor, M. N., Swain, M. G. Role of chemokines and chemokines receptors in the gastrointestinal tract. Immunology 105(2), 137-143, 2002

2. Anton, I. M., Jones, G. E. WIP: a multifunctional protein involved in actin cytoskeleton regulation. Eur. J. Cell. Biochem. 85(3-4), 295-304, 2006.

3. Baron, D., Houlgatte, R., Fostier, A., Guiguen, Y. Large-scale temporal gene expression profiling during gonadal differentiation and early gametogenesis in rainbow trout. Biol. Reprod. 73(5), 959-966, 2005.

4. Blikslager, A. T., Moeser, A. J., Gookin, J. L., Jones, S. L., Odle, J. Restoration of barrier function in injured intestinal mucosa. Physiol. Rev. 87(2), 545-564, 2007.

5. Boudry, G., Péron, V., Le Huërou-Luron, I., Lallès, J. P., Sève, B. Weaning induces both transient and long-lasting modifications of absorptive, secretory, and barrier properties of piglet intestine. J. Nutr. 134(9), 2256-2262, 2004

6. Boudry, G., Cheeseman, C. I., Perdue, M. H. Psychological stress impairs Na+dependent glucose absorption and increases GLUT2 expression in the rat jejunal brushborder membrane. Am. J. Physiol. Reg. Integ. Comp. Physiol. 292(2), R862-R867, 2007

7. Burrin, D., Stoll, B., Van Goudoever, J. B., Reeds, P. J. Nutrients requirements for intestinal growth and metabolism in the developing pigs. In: Digestive physiology of pigs, Lindberg, J. E. and Ogle, B. (Eds), CABI Publishing, Wallingford, UK. 2001; pp78-88.

8. Carey, H. V., Hayden, U. L., Tucker, K. E. Fasting alters basal and stimulated ion transport in piglet jejunum. Am. J. Physiol. Reg. Integ. Comp. Physiol. 267(1), R156R163, 1994. 
9. Chung, T. K, and Baker, D. H. Ideal amino acid pattern for 10-kilogram pigs. J. Anim. Sci. 70(10), 3102-3111, 1992.

10. Cid, M. C., Esparza, J., Schnaper, H. W., Juan, M., Yague, J., Grant, D. S., Urbano-Marquez, A., Hoffman, G. S., Kleinman, H. K. Estradiol enhances endothelial cell interactions with extracellular matrix proteins via an incease in integrin expression and function. Angiogenesis 3(3), 271-280, 1999

11. Coutifaris, C., Omigbodun, A., Coukos, G. The fibronectin receptor alpha5 integrin subunit is upregulated by cell-cell adhesion via a cyclic AMP-dependent mechanism: implication for human trophoblast migration. Am. J. Obstet. Gynecol. 192(4), 1240-1253, 2005

12. Darcy-Vrillon, B., Posho, L., Morel, M. T., Bernard, F., Blachier, F., Meslin, J. C., Duée, P. H. Glucose, galactose, and glutamine metabolism in pig isolated enterocytes during development. Pediatr. Res. 36(2), 175-181, 1994.

13. Deplancke, B., and Gaskins, H. R. Microbial modulation of innate defense: goblet cells and the intestinal mucus layer. Am. J. Clin. Nutr. 73(6), 1131S-1141S, 2001.

14. Didier, G., Brézellec, P., Remy, E., Hénaut, A. GeneANOVA - gene expression analysis of variance. Bioinformatics 18(3), 490-491, 2002.

15. Duée, P. H., Darcy-Vrillon, B., Blachier, F., Morel, M. T. Fuel selection in intestinal cells. Proc. Nutr. Soc. 54(1), 83-94, 1995.

16. Eisen, M. B., Spellman, P. T., Brown, P. O., Botstein, D. Cluster analysis and display of genome-wide expression pattern. Proc. Natl. Acad. Sci. USA. 95(25), 1486314868, 1998. 
17. Faure, M., Moennoz, D., Montigon, F., Mettraux, C., Breuillé, D., Ballèvre, O. Dietary threonine restriction specifically reduces intestinal mucin synthesis in rats. J. Nutr. 135(3), 486-491, 2005

18. Fellermann, K., and Stange, E. F. Defensins - innate immunity at the epithelial frontier. Eur. J. Gastroenterol. Hepatol. 13(7), 771-776, 2001.

19. Goodlad, R. A., Levi, S., Lee, C. Y., Mandir, N., Hodgson, H., Wright, N.A. Morphometry and cell proliferation in endoscopic biopsies: valuation of a technique. Gastroenterology 101(5), 1235-1241, 1991.

20. Hamard, A., Sève, B., Le Floc'h, N. Intestinal development and growth performance of early-weaned piglets fed a low-threonine diet. Animal 1(8), 1134-1142, 2007.

21. Hamard, A., Sève, B., Le Floc'h, N. A moderate threonine deficiency affects differently protein metabolism in tissues of early-weaned piglets. Comp. Biochem. Physiol. A Mol. Integr. Physiol. In press, 2008.

22. Jin, M., He, S., Wörpel, V., Ryan, S. J., Hinton, D. R. Promotion of adhesion and migration of RPE cells to provisional extracellular matrices by TNF-alpha. Invest. Ophthalmol. Vis. Sci. 41(13), 4324-4332, 2000

23. Juliano, R. L, Reddig, P., Alahari, S., Edin, M., Howe, A., Aplin, A. Integrin regulation of cell signalling and motility. Biochem. Soc. Transactions 32(3), 443-446, 2004.

24. Kansagra, K., Stoll, B., Rognerud, C., Niinikoski, H., Ou, C.-N., Harvey, R., Burrin, D. Total parenteral nutrition adversely affects gut barrier function in neonatal piglets. Am. J. Physiol. Gastrointest. Liver Physiol. 285(6), G1162-G1170, 2003

25. Kimball, S. R. Regulation of global and specific mRNA translation by amino acids. $J$. Nutr. 132(5), 883-886, 2002. 
26. Kuwada, S. K., Li, X. Integrin alpha5/beta1 mediates fibronectin-dependent epithelial cell proliferation through epidermal growth factor receptor activation. Mol. Biol. Cell. 11(7), 2485-2496, 2000.

27. Law, G. K., Bertolo, R.,F., Adjiri-Awere, A., Pencharz, P. B., Ball, R. O. Adequate oral threonine is critical for mucin production and gut function in neonatal piglets. Am. $J$. Physiol. Gastrointest. Liver Physiol. 292(5), G1293-G1301, 2007.

28. Le Floc'h, N. and Sève, B. Catabolism through the threonine dehydrogenase pathway does not account for the high first-pass extraction rate of dietary threonine by the portal drained viscera in pigs. Br. J. Nutr. 93(4), 447-456, 2005.

29. Lien, K. A., Sauer, W. C., Fenton, M. Mucin output in ileal digesta of pigs fed a proteinfree diet. Z. Ernährungswiss. 36(2), 182-190, 1997.

30. Mantle, M., and Allen, A. Isolation and characterization of the native glycoprotein from pig small-intestinal mucus. Biochem. J. 195(1), 267-275, 1981.

31. Mazurais, D. Montfort, J., Delalande, C., LeGac, F. L. Transcriptional analysis of testis maturation using trout cDNA microarray. Gen. Comp. Endocrinol. 142(1-2), 143-154, 2005

32. Mitic, L. L., Van Itallie, C. M., Anderson, J. M. Molecular physiology and pathophysiology of tight junctions I. Tight junction structure and function: lessons from mutant animals and proteins. Am. J. Physiol. Gastrointest. Liver Physiol. 279(2), G250G254, 2000.

33. Montagne, L., Piel, C., Lallès, J. P. Effect of diet on mucin kinetics and composition: nutrition and health implications. Nutr. Rev. 62(3), 105-114, 2004. 
34. Musch, M. W., Walsh-Reitz, M. M., Chang, E. B. Roles of ZO1, occluding and actin in oxidant-induced barrier disruption. Am. J. Physiol. Gastrointest. Liver Physiol. 290(2), G222-G231, 2006.

35. Pagmantidis, V., Bermano, G., Villette, S., Broom, I., Arthur, J., Hesketh J. Effect of Se-depletion on glutathione peroxidase and selenoprotein $\mathrm{W}$ gene expression in the colon. FEBS Lett. 579(3), 792-796, 2005.

36. Pannellini, T., Tezzi, M., Di Carlo, E., Eleuterio, E., Coletti, A., Modesti, A., Rosini, S., Neri, M., Musiani, P. The expression of LEC/CCL16, a powerful proinflammatory chemokine, is upregulated in ulcerative colitis. Int. J. Immunopathol. Pharmacol. 17(2), 171-180, 2004.

37. Piel, C., Montagne, L., Salgado, P., Lallès, J. P. Estimation of ileal output of gastrointestinal glycoprotein in weaned piglets using three different methods. Reprod. Nutr. Dev. 44(5), 419-435, 2004.

38. Pizzuti, D., Bortolami, M., Mazzon, E., Buda, A., Guariso, G., D’Odorico, A., Chiarelli, S., D’Incà, R., De Lazzari, F., Martines, D. Transcriptional downregulation of tight junction protein ZO-1 in active celiac disease is reversed after a gluten-free diet. Dig. Liver Dis. 36(5), 337-341 2004.

39. Poritz, L. S., Garver, K. I., Green, C., Fitzpatrick, L., Ruggiero, F., Koltun, W. A. Loss of the tight junction proteins ZO-1 in dextran sulphate sodium induced colitis. $J$. Surg. Res. 140(1), 12-19, 2007.

40. Rerat, A., Simoes-Nunes, C., Mendy, F., Vaissade, P., Vaugelade, P. Splanchnic fluxes of amino acids after duodenal infusion of carbohydrate solutions containing free amino acids or oligopeptides in the non-anaesthetized pig. Br. J. Nutr. 68(1), 111-138, 1992. 
41. Stoll, B., Henry, J., Reeds, P. J., Yu, H., Jahoor, F., Burrin, D. Catabolism dominates the first-pass intestinal metabolism of dietary essential amino acids in milk protein-fed piglets. J. Nutr. 128(9), 606-614, 1998.

42. Turner, J. R., Rill, B. K., Carlson, S. L., Carnes, D., Kerner, R., Mrsny, R. J., Madara, J. L. Physiological regulation of epithelial tight junctions is associated with myosin light-chain phosphorylation. Am. J. Physiol. Regulatory Integrative Comp. Physiol. 273(4), C1378-C1385, 1997.

43. Van der Schoor, S. R. D., Wattimena, D. L., Huijmans, J., Vermes A., Van Goudoever, J. B. The gut takes nearly all:threonine kinetics in infants. Am. J. Clin. Nutr. 86(4), 1132-1138, 2007.

44. Wang, X., Qiao, S., Yin, Y., Yue, L., Wang, Z., Wu, G. A deficiency or excess of dietary threonine reduces protein synthesis in jejunum and skeletal muscle of young pigs. J. Nutr. 137(6), 1442-1446, 2007.

45. Wang, Q. Y., Zhang, Y., Shen, S. H., Chen, H. L. Alpha1,3 fucosyltransferase-VII upregulates the mRNA of alpha5 integrin and its biological function. J. Cell. Biochem. 104(6), 2078-2090, 2008.

46. Wu, G., Fang, Y. Z., Yang, S., Lupton, J. R., Turner, N. D. Glutathione metabolism and its implication in health. J. Nutr. 134(3), 489-492, 2004.

47. Zhang, J., Li, W., Sanders, M. A., Sumpio, B. E., Panja, A., Basson, M. D. Regulation of the intestinal response to cyclic strain by extracellular matrix proteins. FASEB J. 17(8), 926-928, 2003. 


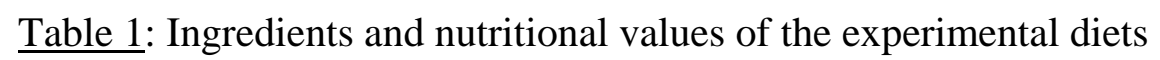

Diet

Low threonine Control

(LT)

(C)

\begin{tabular}{lcc}
\hline Ingredients, g /kg diet & & \\
Skimmed milk powder & 250 & 250 \\
Soluble fish protein concentrate & 74.3 & 74.3 \\
Free amino acids mix ${ }^{1}$ & 54.9 & 54.9 \\
Maltodextrins & 430.15 & 430.44 \\
Sunflower oil & 62.37 & 62.37 \\
Ammonium citrate tribasic & 30 & 30 \\
Bicalcium phosphate & 49 & 49 \\
Trace element and vitamin premix ${ }^{2}$ & 10 & 36.48 \\
L-aspartic acid & 39.28 & 2.51 \\
L-threonine & - & 15 \\
Chemical analysis & 15 & 92.8 \\
Dry matter, \% & 92.9 & 25 \\
Crude protein (N x 6.25), \% & & \\
Digestible energy, MJ/kg diet & & \\
\hline
\end{tabular}

${ }^{1}$ Supplying the following amount of free amino acids (g / kg diet): L-lysine HCl, 3.53; Ltryptophane, 0.85; L-leucine, 1.86; L-isoleucine, 1.35; L-valine, 1.39; L-phenylalanine, 1.42; L-glutamate monoNa /A. glutamique (50/50), 35.3; glycine, 9.2.

${ }^{2}$ Supplying the following amount of vitamins and minerals (per kg diet): Ca, 1.82 g; Fe, 200 mg; Cu, 40 mg; Zn, 200 mg; Mn, 80 mg; Co, 4 mg; Se 0.6 mg; I, 2 mg; vitamin A, 30,000 UI; 
vitamin D3, 6000 UI; vitamin E, 80 UI; vitamin B1, 4 mg; vitamin B2, 20 mg; panthotenic acid, 30 mg; vitamin B6, 20 mg; vitamin B12, 0.1 mg; vitamin PP, 60 mg; folic acid, 4 mg; vitamin K3, 4 mg; biotin, 0.4 mg; choline, 1600 mg; vitamin C, 200 mg. 
2

\begin{tabular}{|c|c|c|c|c|}
\hline Gene & Protein name & Forward primer & Reverse primer & $\begin{array}{c}\text { Accession } \\
\text { no. }\end{array}$ \\
\hline GAPDH & Glyceraldehyde-3-phosphate dehydrogenase & CATCCATGACAACTTCGGCA & GCATGGACTGTGGTCATGAGTC & AF017079 \\
\hline TJP1 & Tight junction protein ZO-1 & AGGCGATGTTGTATTGAAGATAAATG & TTTTTGCATCCGTCAATGACA & CK453343 \\
\hline SGLT1 & Sodium/glucose cotransporter 1 & CCCAAATCAGAGCATTCCATTCA & AAGTATGGTGTGGTGGCCGGTT & DY417361 \\
\hline CGN & Cingulin & GTTAAAGAGCTGTCCATCCAGATTG & CTTAGCTGGTCTTTCTGGTCATTG & DN116728 \\
\hline
\end{tabular}
3

4 The primers were designed using Primer Express Software (Applied Biosystems) based on sus scrofa published nucleotide sequences (Iccare;

5 http://bioinfo.genopole-toulouse.prd.fr/Iccare/). 
Table 3: Growth performance of piglets pair-fed either a well balanced control diet (C: $9.3 \mathrm{~g}$ threonine / kg diet) or a low threonine diet (LT: $6.5 \mathrm{~g}$ threonine / kg diet) for 2 weeks.

\begin{tabular}{|c|c|c|c|c|}
\hline & \multicolumn{2}{|c|}{ Diet } & \multirow[b]{2}{*}{ sem } & \multirow[b]{2}{*}{$\mathrm{p}$} \\
\hline & $\mathrm{C}$ & $\mathrm{LT}$ & & \\
\hline Initial weight, kg(day 0) & 2.57 & 2.56 & 0.01 & NS \\
\hline Final weight, kg (day 14) & 4.54 & 4.52 & 0.06 & NS \\
\hline BW gain, kg / d & 0.130 & 0.131 & 0.004 & NS \\
\hline Feed intake, g / kg BW ${ }^{0.75} \cdot \mathrm{d}^{-1}$ & 51.7 & 51.8 & 0.74 & NS \\
\hline Thr intake, g / kg BW ${ }^{0.75} \cdot \mathrm{d}^{-1}$ & 0.48 & 0.34 & 0.006 & $<0.0001$ \\
\hline
\end{tabular}

Values are LSmeans for $\mathrm{n}=7$ piglets. sem are standard error of the mean. 
Table 4: Small intestinal morphology of piglets pair-fed either a well balanced control diet (C:

$9.3 \mathrm{~g}$ threonine / kg diet) or a low threonine diet (LT: $6.5 \mathrm{~g}$ threonine / kg diet) for 2 weeks.

\begin{tabular}{|c|c|c|c|c|}
\hline & \multicolumn{2}{|c|}{ Diet } & \multirow[b]{2}{*}{ sem } & \multirow[b]{2}{*}{$\mathrm{p}$} \\
\hline & $\mathrm{C}$ & $\begin{array}{l}\mathrm{LT} \\
\mathrm{L}\end{array}$ & & \\
\hline \multicolumn{5}{|l|}{ Jejunum proximal } \\
\hline villous height, $\mu \mathrm{m}$ & 623 & 653 & 36 & NS \\
\hline villous surface, $\mu \mathrm{m}^{2}$ & 105008 & 99303 & 7389 & NS \\
\hline crypt depth, $\mu \mathrm{m}$ & 149 & 145 & 6 & NS \\
\hline \multicolumn{5}{|l|}{ Jejunum distal } \\
\hline villous height, $\mu \mathrm{m}$ & 568 & 586 & 39 & NS \\
\hline villous surface, $\mu \mathrm{m}^{2}$ & 89384 & 86907 & 6189 & NS \\
\hline crypt depth, $\mu \mathrm{m}$ & 161 & 156 & 7 & NS \\
\hline \multicolumn{5}{|l|}{ Ileum } \\
\hline villous height, $\mu \mathrm{m}$ & 591 & 518 & 23 & 0.06 \\
\hline villous surface, $\mu m^{2}$ & 81668 & 67197 & 2589 & 0.007 \\
\hline crypt depth, $\mu \mathrm{m}$ & 150 & 146 & 4 & NS \\
\hline
\end{tabular}

Values are LSmeans for $n=7$. sem are standard error of the mean. 
Table 5: Glucose-induced changes in short-circuit current in the ileum of early weaned piglets pair-fed either a well balanced control diet (C: $9.3 \mathrm{~g}$ threonine / kg diet) or a low threonine diet (LT: $6.5 \mathrm{~g}$ threonine / kg diet) for 2 weeks.

\begin{tabular}{lcccc}
\hline & \multicolumn{3}{c}{ Diet } & \\
\cline { 2 - 3 } & $\mathrm{C}$ & $\mathrm{LT}$ & sem & $\mathrm{P}$ \\
\hline $\mathrm{V}_{\max }, \mu \mathrm{A} / \mathrm{cm}^{-2}$ & 68.98 & 124.83 & 19.54 & 0.10 \\
$\mathrm{~K}_{\mathrm{m}}, \mathrm{mM}$ & 4.93 & 4.10 & 0.91 & $\mathrm{NS}$ \\
\hline
\end{tabular}

Values are LSmeans for $n=7$. sem are standard error of the mean. 
Figure titles and legends

Fiqure 1: Variation of delta $I_{\mathrm{SC}}$, in response to increasing dose of glucose, in the ileum of piglets pair-fed either a well balanced control diet (C: 9.3 g threonine / kg diet; dotted line) or a low threonine diet (LT: $6.5 \mathrm{~g}$ threonine / kg diet; full line) for 2 weeks. Tissues were mounted in Ussing chambers and graded doses of glucose were added to the mucosal side every 5 min, osmotically balanced on the serosal side by mannitol. The maximal increase in $\mathrm{I}_{\mathrm{SC}}$ (delta $\mathrm{I}_{\mathrm{SC}}$ ) after addition of each dose of glucose was recorded. Values are LSmeans \pm sem, $\mathrm{n}=7$. * difference between LT and C piglets, $\mathrm{p}<0.05$.

Fiqure 2: FITC dextran 4000 Da flux $\left(\mathrm{ng} / \mathrm{cm}^{-2} \cdot \mathrm{h}^{-1}\right)$ across the ileum of piglets pair-fed either a well balanced control diet (C: $9.3 \mathrm{~g}$ threonine / kg diet, white bar) or a low threonine diet (LT: $6.5 \mathrm{~g}$ threonine/kg diet, black bar) for 2 weeks. Tissues were mounted in Ussing chambers. FITC dextran 4000 (FD4) was added on the mucosal side at the final concentration of $0.375 \mathrm{mg} / \mathrm{mL}$. Its transport was monitored by sampling solution from the serosal side at 30min intervals for 120 minutes. After measuring FD4 concentrations in the samples, the flux over the 120 min period was calculated. Values are LSmeans \pm sem, $\mathrm{n}=7$. * difference between LT and C piglets, $\mathrm{p}<0.05$.

Fiqure 3: Transepithelial resistance (ohms $/ \mathrm{cm}^{-2}$ ) in the ileum of piglets pair-fed either a well balanced control diet (C: 9.3 g threonine/kg diet, white bar) or a low threonine diet (LT: $6.5 \mathrm{~g}$ threonine/kg diet) for 2 weeks. Tissues were mounted in Ussing chambers and the transepithelial resistance measured after 20 min-equilibrium. Values are LSmeans \pm sem, $n=$ 7. 
Fiqure 4: Relative mRNA abundance of the sodium/glucose cotransporter 1 (SGLT-1, A), the tight junction protein (ZO-1, B) and cingulin (CGN, C) in ileum of piglets pair-fed either a well balanced control diet (C: 9.3 g threonine / kg diet, white bar) or a low threonine diet (LT: $6.5 \mathrm{~g}$ threonine/kg diet, black bar) for 2 weeks. Target gene was expressed relatively to GAPDH level. Values are LSmeans \pm sem, $\mathrm{n}=7$. * difference between LT and C piglets, $\mathrm{p}<0.05$.

Supplemental Table 1 Genes overexpressed in the ileum of piglets fed a low threonine diet (LT: $6.5 \mathrm{~g}$ threonine / kg diet) for two weeks $(\mathrm{n}=7)$.

Supplemental Table 2 Genes downexpressed in the ileum of piglets fed a low threonine diet (LT: $6.5 \mathrm{~g}$ threonine/kg diet) for two weeks $(\mathrm{n}=7)$. 
Fiqure 1

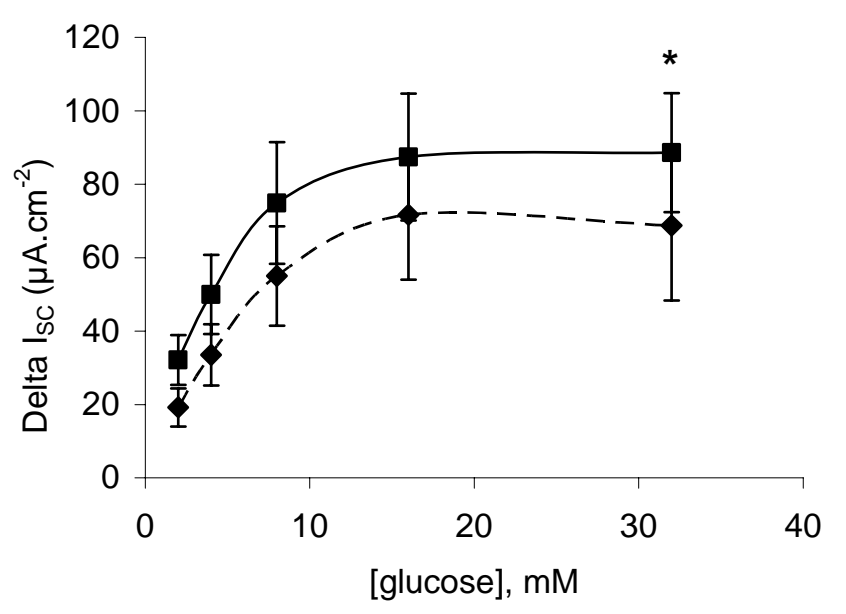


Fiqure 2

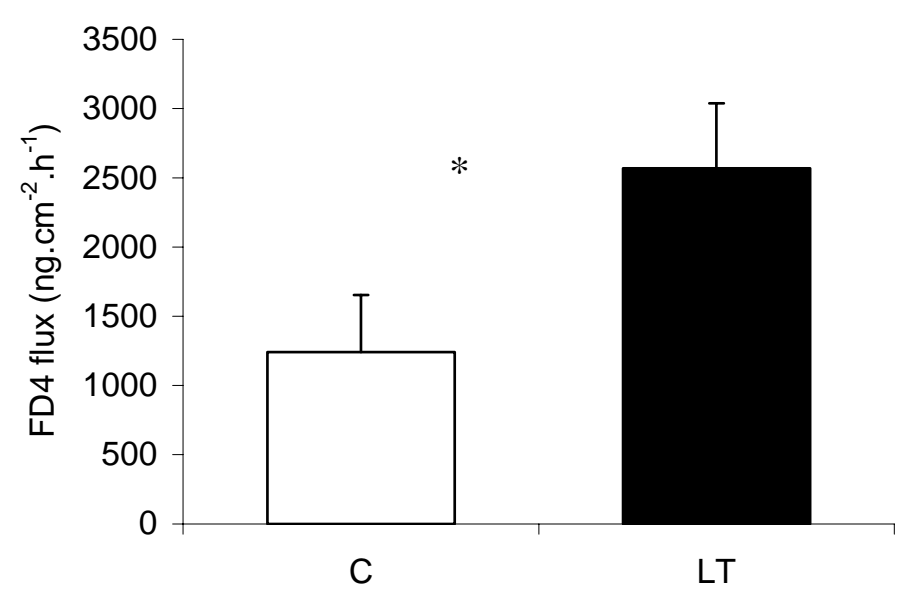


Fiqure 3

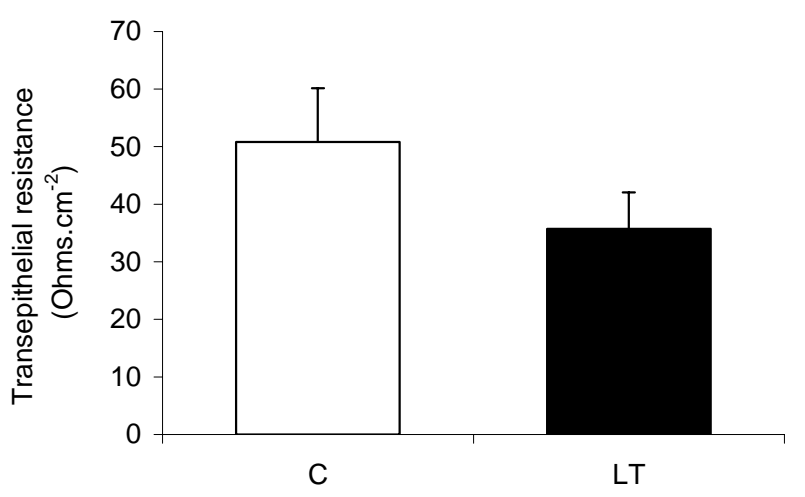


Fiqure 4

A

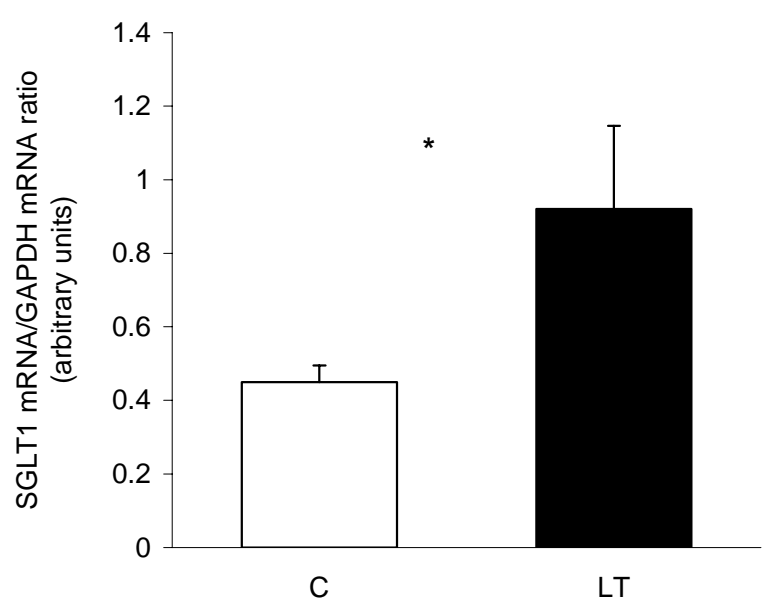

B

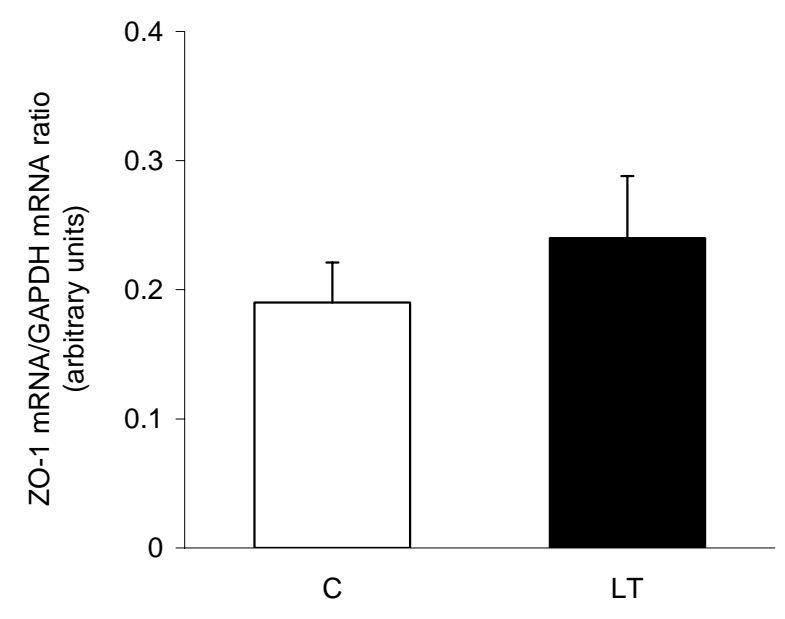

C

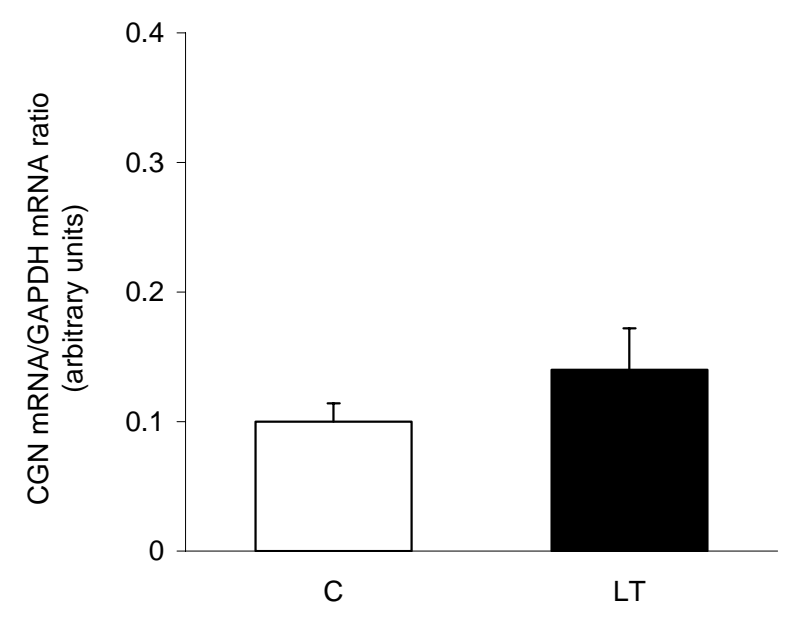


Supplemental Table 1: Genes overexpressed in the ileum of piglets fed a low threonine diet (LT: $6.5 \mathrm{~g}$ threonine/kg diet) for two weeks

\begin{tabular}{|c|c|c|c|c|c|}
\hline SS & CONTIG & GENE & $\begin{array}{c}\text { Ratio } \\
\text { (LT/C) }\end{array}$ & $\begin{array}{l}\text { SWISS PROT TENTATIVE DESCRIPTION } \\
\text { (highest similarity) }\end{array}$ & BIOLOGICAL PROCESS GO \\
\hline \multicolumn{6}{|c|}{ Immune and defense responses (13) } \\
\hline $\begin{array}{l}\text { scan0016.e.02 } \\
\text { scab0141.i.24 } \\
\text { scab0055.b.04 } \\
\text { scan0030.g.11 } \\
\text { scac0025.0.07 } \\
\text { scan0003.l.18 } \\
\text { scan0007.b.20 } \\
\text { scac0025.p.05 } \\
\text { scab0109.b.13 } \\
\text { scan0013.l.17 } \\
\text { scan0021.g.16 } \\
\text { scaj0003.d.05 } \\
\text { scaa0081.l.15 }\end{array}$ & $\begin{array}{l}\text { BM484902 } \\
\text { BG384365 } \\
\text { BF081123 } \\
\text { BX916389 } \\
\text { CB097354 } \\
\text { CB286296 } \\
\text { BP156850 } \\
\text { BM658975 } \\
\text { CF362072 } \\
\text { BM659897 } \\
\text { CA780101 } \\
\text { AJ275263 } \\
\text { CO994920 } \\
\end{array}$ & $\begin{array}{l}\text { C1S } \\
\text { IL17RB } \\
\text { CCR4 } \\
\text { CCL16 } \\
\text { DARC } \\
\text { PTPRCAP } \\
\text { CD6 } \\
\text { HLA-B } \\
\text { FCER1A } \\
\text { SEPW1 } \\
\text { DEFB129 } \\
\text { MGST1 } \\
\text { MUC1 }\end{array}$ & $\begin{array}{l}1.85 \\
2.64 \\
2.14 \\
2.07 \\
1.73 \\
2.39 \\
2.07 \\
1.87 \\
1.71 \\
1.95 \\
2.72 \\
2.66 \\
2.03 \\
\end{array}$ & $\begin{array}{l}\text { Complement C1s subcomponent precursor } \\
\text { Interleukin-17 receptor B precursor } \\
\text { C-C chemokine receptor type } 4 \\
\text { C-C motif chemokine } 16 \text { (precursor) } \\
\text { Duffy antigen/chemokine receptor } \\
\text { Protein tyrosine phosphatase receptor type C-associated protein } \\
\text { T-cell differentiation antigen CD6 precursor } \\
\text { MHC class I antigen } \\
\text { High affinity immunoglobulin epsilon receptor alpha-subunit precursor } \\
\text { Selenoprotein W } \\
\text { Beta-defensin } 129 \\
\text { Microsomal glutathione S-transferase } 1 \text { (EC 2.5.1.18) } \\
\text { Mucin-1 precursor }\end{array}$ & $\begin{array}{l}\text { Complement activation } \\
\text { Defense response } \\
\text { Inflammatory response; Chemotaxis } \\
\text { Inflammatory response ; Chemotaxis } \\
\text { Defence response } \\
\text { Defence response } \\
\text { Immune response } \\
\text { Antigen processing and presentation of peptide antigen } \\
\text { Immune response } \\
\text { Cell redox homeostasis } \\
\text { Antimicrobial response } \\
\text { Gluthatione metabolic process } \\
\text { Defence response }\end{array}$ \\
\hline \multicolumn{6}{|c|}{ Cell cycle, proliferation, differentiation and death (4) } \\
\hline $\begin{array}{l}\text { scan001.j.10 } \\
\text { scab0053.l.23 } \\
\text { scan0002.b.07 } \\
\text { scaj0001.d.04 } \\
\end{array}$ & $\begin{array}{l}\text { CK460804 } \\
\text { CF361784 } \\
\text { CF793806 } \\
\text { CF176213 } \\
\end{array}$ & $\begin{array}{l}\text { BID } \\
D A P K 1 \\
I G F 2^{*} \\
\text { CDK5RAP2 } \\
\end{array}$ & $\begin{array}{l}2.61 \\
1.93 \\
1.56 \\
1.80 \\
\end{array}$ & $\begin{array}{l}\text { BH3 interacting domain death agonist } \\
\text { Death-associated protein kinase } 1 \text { (EC 2.7.1.37) } \\
\text { Insulin-like growth factor II precursor (IGF-II) } \\
\text { CDK5 regulatory-subunit associated protein } 2 \\
\end{array}$ & $\begin{array}{l}\text { Induction of apoptosis } \\
\text { Induction of apoptosis } \\
\text { Cell proliferation } \\
\text { Regulation of neuron differentiation } \\
\end{array}$ \\
\hline \multicolumn{6}{|c|}{ Transport (13) } \\
\hline Scan0037.g.15 & BX917979 & SLC24A4 & 2.03 & Sodium/potassium/calcium exchanger 4 precursor & Ion transport \\
\hline Scan0002.a.16 & BX921422 & PXYD1 & 1.71 & $\begin{array}{l}\text { Phospholemnan precursor (FXYD domain-containing ion transport } \\
\text { regulator 1) }\end{array}$ & Chloride transport \\
\hline Scac0036.g.11 & CA679461 & SGLT-1 & 4.9 & Sodium/glucose cotransporter 1 & Glucose cotransport \\
\hline Scan0002.b.09 & BQ598790 & SLC7A7 & 2.60 & $\mathrm{Y}+\mathrm{L}$ amino acid transporter $1(\mathrm{y}+\mathrm{LAT}-1)$ & AA transport \\
\hline scaa0081.i.16 & BP435185 & SCNN1B & 2.01 & Amiloride-sensitive sodium channel beta-subunit & Sodium transport \\
\hline scac0036.g.05 & BQ597494 & ATP6V0A2 & 2.19 & Vacuolar protein translocating ATPase $116 \mathrm{kDA}$ subunit A isoform 2 & Ion transport \\
\hline Scac0040.g.18 & BQ603902 & TMEM9 & 2.10 & Transmembrane protein 9 precursor & Intracellular transport \\
\hline Scan0018.j.21 & BP450608 & KTN1 & 1.78 & Kinectin (Kinesin receptor) & Cytoskeleton-dependent intracellular transport \\
\hline Scan0009.c.23 & CF791942 & ACTR1B & 1.63 & Beta-centractin (Actin-related protein 1B) & Cytoskeleton-dependent intracellular transport \\
\hline scan0021.i.09 & CK465736 & GOLGA5 & 2.10 & Golgin subfamily A member 5 & Golgi vesicle transport \\
\hline scan0023.m.02 & BQ605161 & KPNA1 & 1.53 & Importin alpha- 1 subunit & Import into nucleus \\
\hline scag0003.c.04 & CF179098 & SLC33A1 & 2.02 & Acetyl-coenzyme A transporter 1 (AT-1) & Acetyl CoA transport \\
\hline Scan0018.j.06 & BM658973 & MTCH2 & 1.95 & Mitochondrial carrier homolog 2 & Transport \\
\hline
\end{tabular}




\section{Cell communication, cell adhesion and cytoskeleton (13)}

\begin{tabular}{|c|c|c|c|c|c|}
\hline scab0083.n.09 & BP152573 & EFNA4 & 2.28 & Ephrin-A4 precursor & Cell-cell signalling \\
\hline scaa0084.o.07 & AW311973 & GJB5 & 2.60 & Gap junction beta-5 protein (Connexin-31.1) & Connexon channel activity \\
\hline scan0012.p.21 & CF367574 & TJP1* & 2.22 & Tight junction protein ZO-1 (Zonula occludens 1 protein) & Cell-cell junction assembly \\
\hline scab0007.b.16 & CF791490 & $C G N^{*}$ & 1.93 & Cingulin & Cell-cell junction assembly \\
\hline scac0028.p.11 & CF176162 & $P X N$ & 1.53 & Paxillin & Cell-matrix adhesion \\
\hline scan0006.d.21 & BX920748 & CELSR2 & 1.84 & Cadherin EGF LAG seven-pass G-type receptor 2 & Cell-cell adhesion \\
\hline scac0033.g.12 & BX670372 & PLEC1 & 1.70 & Plectin 1(Hemidesmosal protein 1) & Cell adhesion \\
\hline scaa0085.g.04 & BE236040 & CO9A1 & 1.91 & Collagen alpha 1 (IX) & Cell adhesion \\
\hline scan0016.c.12 & CF177583 & ITGA5 & 2.12 & Integrin alpha-5 precursor (Fibronectin receptor subunit alpha) & Cell adhesion \\
\hline scan0005.k.13 & BP439633 & $N E F M$ & 2.43 & Neurofilament triplet M protein (160 kDa neurofilament protein) & Cytoskeleton organisation \\
\hline scac0028.g.19 & BQ605009 & TMOD1 & 1.70 & Tropomodulin (Erythrocyte tropomodulin) (E-Tmod) & Cytoskeleton organisation \\
\hline scan0001.c.12 & BX914440 & WIPF1 & 2.43 & Wiskott-Aldrich syndrome protein interacting protein homolog & Cytoskeleton organization \\
\hline scan0016.d.21 & BX924036 & TPM1 & 2.85 & Tropomyosin 1 & Cytoskeleton organisation \\
\hline \multicolumn{6}{|c|}{ Regulation of transcription and RNA metabolism (15) } \\
\hline scag0003.c.05 & BQ603934 & POLR2B & 1.82 & \multirow{5}{*}{$\begin{array}{l}\text { DNA_directed RNA polymerase II } 140 \text { kDa polypeptide (EC 2.7.7.6) } \\
\text { RNA polymerase-associated protein } 1 \\
\text { Transcription initiation factor IIE alpha subunit (General transcription } \\
\text { factor TFIIE-alpha) } \\
\text { Transcription initiation factor IIB (General transcription factor TFIIB) } \\
\text { Transcription factor BTEB1 (Basic transcription element binding } \\
\text { protein 1) }\end{array}$} & Transcription initiation \\
\hline scac0031.i.17 & CB480365 & PAF1 & 1.38 & & Transcription initiation \\
\hline scaa0084.b.16 & CB483014 & GTF2E1 & 1.73 & & Transcription initiation \\
\hline scan0013.a.02 & BQ599964 & GTF2B & 1.81 & & Transcription initiation \\
\hline scan0024.i.12 & BX923131 & KLF9 & 2.67 & & Regulation of transcription \\
\hline scan0012.d.08 & BQ605150 & SMARCA2 & 2.07 & Possible global transcription activator SNF2L2 & Regulation of transcription \\
\hline scab0085.k.15 & BP153501 & MTF2 & 1.81 & Metal-response element-binding transcription factor 2 & Regulation of transcription \\
\hline scac0025.g.18 & CF787149 & ZNF644 & 3.00 & Zinc finger protein 644 & Regulation of transcription \\
\hline scan0006.d.14 & BX920743 & ZNF169 & 1.74 & Zinc finger protein 169 & Regulation of transcription \\
\hline scag0003.c.03 & BX665395 & ZFP161 & 1.89 & Zinc finger protein 161 & Regulation of transcription \\
\hline scan0028.f.03 & BQ597361 & TRIP4 & 1.72 & Thyroid hormone receptor interactor 4 & Regulation of transcription \\
\hline scan0011.j.19 & BQ599264 & SF3B14 & 1.85 & Pre-mRNA branch site protein p14 (SF3B 14 kDa subunit) & RNA splicing \\
\hline Scac0027.p.17 & CF788806 & CWF18 & 1.94 & Cell cycle control protein cwf18 & RNA splicing \\
\hline scac0032.1.09 & BX671553 & ADARB2 & 1.73 & Double-stranded RNA-specific editase B2 & RNA processing \\
\hline scac0032.n.01 & BQ601512 & SERBP1 & 2.22 & Plasminogen activator inhibitor 1 RNA-binding protein & Regulation of mRNA stability \\
\hline
\end{tabular}

\section{Cellular protein metabolism (10)}

\begin{tabular}{|c|c|c|c|c|}
\hline scan0003.c.10 & CA779705 & DNJB9 & 1.86 & DnaJ homolog subfamily B member 9 \\
\hline scan0036.a.17 & CA778605 & PPIF & 1.66 & $\begin{array}{l}\text { Peptidyl-prolyl cis-trans isomerase, mitochondrial precursor (EC } \\
\text { 5.2.1.8) }\end{array}$ \\
\hline Scac0026.o.24 & BX666928 & STUB1 & 2.00 & STIP1 homology and U box-containing protein 1 (EC 6.3.2.-) \\
\hline Scac0034.g.21 & BM675718 & $M P P B$ & 1.63 & Mitochondrial processing peptidase beta subunit \\
\hline Scac0033.p.20 & CB472986 & FBXW4 & 1.61 & F-box/wd-repeat protein 4 (Dactylin) \\
\hline
\end{tabular}

Protein folding

Protein folding

Positive regulation of protein ubiquitination Proteolysis

Ubiquitin-dependent protein catabolic process 


\begin{tabular}{|c|c|c|c|c|c|}
\hline scan0022.f.09 & BQ599441 & ZMPSTE24 & 2.38 & CAAX prenyl protease 1 homolog (EC 3.4.24.84) & Proteolysis \\
\hline scan0023.a.05 & BM659723 & $V C P$ & 2.20 & Transitional endoplasmic reticulum ATPase & ER-associated protein catabolic process \\
\hline scan0031.a.12 & CB471256 & TSSC1 & 1.83 & Protein TSSC1 & Protein binding \\
\hline scan0020.a.05 & BX921900 & MTIF2 & 1.90 & Translation initiation factor IF-2, mitochondrial precursor & Regulation of translational initiation \\
\hline Scac0027.g.18 & BQ597589 & RT10 & 1.63 & Mitochondrial 28S ribosomal protein S10 (S10mt) & Translation \\
\hline \multicolumn{6}{|c|}{ Signal transduction (10) } \\
\hline scac0034.i.03 & CA780698 & APLP2 & 2.30 & Amyloid-like protein 2 precursor & G-protein coupled receptor protein signalling pathway \\
\hline scac0033.g.11 & BO597942 & $C A L C R$ & 1.84 & Calcitonin receptor precursor & G-protein coupled receptor protein signalling pathway \\
\hline scan0010.b.03 & BX922704 & GPR124 & 1.98 & Probable G-protein coupled receptor 124 precursor & G-protein coupled receptor protein signalling pathway \\
\hline scan0025.c.02 & BX921688 & PAK4 & 2.60 & Serine/threonine-protein kinase PAK 4 (EC 2.7.1.37) & Signal transduction \\
\hline scan0003.b.04 & BQ602864 & $R A P 1 A$ & 1.62 & Ras-related protein Rap-1A (Ras-related protein Krev-1) & Signal transduction \\
\hline scaj0013.m.20 & & GAP & 2.10 & GTPase-activating protein GAP & Signal transduction \\
\hline scan0025.c.08 & CF364431 & $C A M K 2 B$ & 2.37 & $\begin{array}{l}\text { Calcium/calmodulin-dependent protein kinase type II beta chain (EC } \\
\text { 2.7.1.123) }\end{array}$ & Signal transduction \\
\hline scan0006.g.02 & BQ598573 & IRS1 & 1.87 & Insulin receptor substrate 1 & Insulin receptor signalling pathway \\
\hline scaa0064.k.04 & AW485812 & LTBP2 & 2.76 & Latent transforming growth factor-beta-binding protein 2 precursor & TGF $\beta$ receptor signalling pathway \\
\hline scaa0113.1.01 & AU296045 & ARHGEF4 & 1.88 & $\begin{array}{l}\text { Rho guanine nucleotide exchange factor } 4 \text { (APC-stimulated guanine } \\
\text { nucleotide exchange factor) (Asef) }\end{array}$ & Regulation of Rho protein signal transduction \\
\hline
\end{tabular}

Other biological process (22)

\begin{tabular}{lllll}
\hline scan0035.i.17 & BX916635 & ATP5O & 1.81 & ATP synthase O subunit \\
scan0018.j.07 & CF792524 & NUFM & 2.18 & NADH-ubiquinone oxidoreductase 13 kDa-B subunit (EC 1.6.99.3) \\
scab0081.d.15 & CF175249 & CACP & 2.12 & Carnitine O-acetyl transferase (EC 2.3.1.7) \\
scac0036.n.17 & CF364016 & CPT1B & 1.66 & Carnitine O-palmitoyltransferase I \\
scan0012.o.24 & BX919932 & FAT2 & 2.00 & Peroxisomal-coenzyme A synthetase \\
Scac0040.e.22 & BQ600082 & PECI & 1.83 & Peroxisomal 3,2-trans-enoyl-CoA isomerase (EC 5.3.3.8) \\
scan0005.k.19 & CB286764 & CHKB & 2.24 & Choline/ethanolamine kinase \\
scac0038.e.23 & BM658676 & CP11A & 2.15 & Cytochrome P450 11A1, mitochondrial precursor (EC 1.14.15.6) \\
scan0029.k.16 & BX916139 & CYP21 & 1.88 & Cytochrome P450 XXI (EC 1.14.99.10) \\
scac0034.a.19 & BX670680 & GAMT & 1.78 & Guanidinoacetate N-methyltransferase (EC 2.1.1.2) \\
scan0005.k.05 & BX917589 & MAN2B2 & 2.28 & Mannosidase alpha class 2B member 2 (EC 3.2.1.24) \\
scan0012.f.03 & BM190280 & PHS2 & 2.07 & Glycogen phsopshorylase, muscle form (EC 2.4.1.1) \\
scan0036.m.17 & BX918235 & PCYOX1 & 1.86 & Prenylcysteine oxidase precursor (EC 1.8.3.5) \\
scan0008.b.02 & BX919941 & LZTR1 & 2.19 & Leucine-zipper-like transcriptional regulator 1 \\
scaa0064.h.24 & CN029176 & POU5F1 & 1.76 & POU domain, class 5, transcription factor 1 \\
scag0004.c.10 & BM445302 & ANKRD2 & 2.33 & Ankyrin repeat domain protein 2 \\
scan0038.e.18 & BM190067 & MB & 1.72 & Myoglobin \\
scan0011.k.02 & BQ598464 & AHSP & 1.77 & Alpha-hemoglobin stabilizing protein (Erythroid-associated factor) \\
scan0012.j.07 & BX921917 & F12 & 1.51 & Coagulation factor XII precursor (EC 3.4.21.38) \\
scan0015.f.06 & AJ429264 & NARG1 & 2.63 & NMDA receptor regulated protein 1 \\
scan0034.m.16 & BX917536 & NDST1 & 1.97 & Heparan sulfate N-deacetylase/N-sulfotransferase (EC 2.8.2.8)
\end{tabular}

ATP biosynthetic process

ATP biosynthetic process

Fatty acid metabolism

Fatty acid beta-oxidation

Fatty acid metabolism

Fatty acid metabolism

Phospholipid biosynthetic process

Steroid biosynthetic process

Steroid biosynthetic process

Creatine biosynthetic process

Mannose metabolic process

Glycogen metabolic process

Prenylcystein catabolic process

Anatomical structure morphogenesis

Anatomical structure morphogenesis

Muscle development

Muscle oxygenation

Hemoglobin metabolic process

Blood coagulation

Heparan sulphate proteoglycan process 


\section{\begin{tabular}{lrr} 
scaa.0085.f.12 & CK454646 & PTGER3 \\
\hline Unknown biological process (45)
\end{tabular}}

\begin{tabular}{|c|c|c|c|c|}
\hline scan0013.1.08 & CF181520 & UTX & 1.61 & Ubiquitously transcribed $\mathrm{X}$ chromosome tetratricopeptide repeat protein \\
\hline scac0044.d.24 & BM659499 & POMC & 1.60 & Corticotropin-lipotropin precursor (Pro-opiomelanocortin) (POMC) \\
\hline scan0005.i.07 & BX664905 & UPL2 & 1.83 & E3 ubiquitin protein ligase UPL2 (EC 6.3.2.-) \\
\hline scac0038.g.16 & BX674115 & CRYBA4 & 1.85 & Beta crystallin A4 \\
\hline scac0036.m.12 & BX671984 & ADAM7 & 1.83 & A disintegrin and metalloproteinase domain 7 \\
\hline scan0033.m.17 & BX917829 & REC8L & 2.91 & Meiotic recombination protein REC8-like1 (Cohesin Rec8p) \\
\hline scan0027.k.07 & BM659681 & Serp1 & 1.96 & Stress-associated endoplasmic reticulum protein 1 \\
\hline scac0031.j.21 & BX668576 & & 1.93 & Tsga10ip protein (Fragment) \\
\hline scan0012.m.20 & BX923588 & & 2.05 & UPF0472 protein C16orf72 homolog \\
\hline scan0031.c.11 & BX915954 & & 1.95 & $\begin{array}{l}\text { Scavenger receptor cysteine-rich domain-containing protein } \\
\text { LOC284297 homolog }\end{array}$ \\
\hline scac0035.c.15 & CB287682 & LYSMD1 & 1.76 & LysM and putative peptidoglycan-binding domain-containing protein 1 \\
\hline scac0033.i.01 & CA778419 & FJX1 & 1.99 & Four-jointed box protein 1 \\
\hline scan0035.k.05 & BP452343 & SGF3 & 1.84 & Silk gland factor 3 \\
\hline scan0035.k.04 & BX915677 & SYNPO2L & 1.74 & Synaptopodin 2-like protein \\
\hline scan0028.f.20 & ВX914945 & Srst & 2.47 & Octapeptide-repeat protein $\mathrm{T} 2$ \\
\hline scan0001.n.22 & BX914369 & VPS39 & 2.38 & Vam6/Vps39-like protein \\
\hline scac0030.b.14 & CA780947 & ZFP64 & 1.94 & Zinc finger protein 64 , isoforms 1 and 2 \\
\hline scan0016.a.19 & BX924017 & CMYA5 & 2.22 & Myospryn \\
\hline scag0006.g.10 & BX665429 & PLXND1 & 2.10 & Plexin D1 precursor \\
\hline scab0080.e.08 & CF793796 & DMWD & 2.34 & Dystrophia myotonica-containing WD repeat motif protein \\
\hline scan0027.k.19 & CB471599 & $U B X D 2$ & 1.63 & UBX domain-containing protein 2 \\
\hline Scan0003.n.19 & CB478819 & WDR13 & 2.08 & WD-repeat protein 13 \\
\hline Scac0030.i.21 & BX676540 & $M B R L$ & 1.51 & Membralin \\
\hline Scac0028.p.19 & CF361271 & CU059 & 1.75 & Protein C21orf59 \\
\hline Scac0033.i.08 & BQ599533 & Q3SYV1 & 1.87 & Hypothetical protein MGC127570 \\
\hline Scac0025.g.24 & CF177974 & Q6K322 & 1.74 & Putative vegetative cell wall protein gp1precursor \\
\hline Scac0031.j.15 & BX668567 & Q9BGV3 & 2.82 & Hypothetical protein \\
\hline Scan0012.m.20 & BX923588 & Q6PAX8 & 2.05 & MGC68553 protein \\
\hline Scag0009.c.04 & BQ597597 & Q86v52 & 1.99 & Hypothetical protein MGC39606 \\
\hline Scan0034.1.21 & BQ601418 & U327 & 1.80 & Hypothetical UPF0327 protein \\
\hline Scag0003.c.07 & CB479247 & RIM9 & 1.76 & pH-response regulator protein palI/RIM9 \\
\hline Scan0004.1.22 & BX920964 & YPD8 & 2.40 & Hypothetical protein C05D11.8 in chromosome III \\
\hline Scac0036.0.15 & CA778597 & YMA7 & 1.99 & Hypothetical protein F54F2.7 in chromosome III \\
\hline Scan0003.n.03 & BX920856 & VE4 & 2.42 & Probable protein E4 \\
\hline Scan0026.a.22 & CB474178 & MUTA & 2.01 & Methylmalonyl-CoA mutase (EC 5.4.99.2) \\
\hline Scac0041.n.17 & BX674830 & Q4ITL4 & 2.71 & Lipopolysaccharide kinase \\
\hline scan0007.a.06 & BP149772 & C9orf9 & 1.99 & Uncharacterized protein C9orf9 \\
\hline scab0108.i.02 & AW435883 & CMTM5 & 1.70 & $\begin{array}{l}\text { CKLF-like MARVEL transmembrane domain-containing protein } 5 \\
\text { (Chemokine-like factor superfamily member 5) }\end{array}$ \\
\hline
\end{tabular}




\begin{tabular}{lllll} 
scan0022.d.05 & CB287200 & MS4A8B & 2.27 & Membrane-spanning 4-domains subfamily A member 8B \\
Scac0029.p.23 & BM659898 & BRD2 & 2.11 & Bromodomain containing protein 2 \\
scan0022.e.23 & BX922153 & HS3ST2 & 2.39 & Heparan sulfate glucosamine 3-O-sulfotransferase 2 (EC 2.8.2.29) \\
scan0008.j.15 & CB462875 & Hsp67Bb & 1.68 & Heat shock protein 67B2 \\
scan0017.m.20 & BX923731 & & 1.87 & Hibernation-associated plasma protein HP-27 precursor \\
scan0016.c.03 & BX923065 & GOLGA2 & 2.56 & Golgin subfamily A member 2 \\
Scac0040.g.10 & CF788497 & SPASR & 1.96 & Spastin7 \\
\hline
\end{tabular}

Clones without informative annotation (69): scaa0115.k.03; scac0025.h.05; scac0026.h.18; scac0026.p.12; scac0027.p.16; scac0029.h.18; scac0029.h.23; scac0029.i.04; scac0029.i.24; scac0030.i.18; scac0030.j.10; scac0031.j.20; scac0031.j.22; scac0031.k.01; scac0032.d.11; scac0032.1.10; scac0033.o.21; scac0036.e.16; scac0036.f.07; scac0036.f.17; scac0036.n.07; scac0040.e.07; scac0041.l.21; scac0042.m.12; scac0043.a.01; scag0002.c.04; scag0003.c.10; scag0003.h.12; scag0004.b.09; scag0005.g.02; scag0006.g.12; scag0011.g.04; scaj0012.k.12; scan0003.b.17; scan0003.n.07; scan0003.o.10; scan0004.n.08; scan0005.j.10; scan0006.g.20; scan0007.b.24; scan0008.j.09; scan0009.n.17; scan0009.o.16; scan0010.a.09; scan0010.n.02; scan0011.i.01; scan0011.j.20; scan0012.f.06; scan0012.m.14; scan0012.n.24; scan0012.p.04; scan0016.b.06; scan0016.d.23; scan0018.j.05; scan0018.j.08; scan0018.j.16; scan0019.b.07; scan0019.c.09; scan0021.f.20; scan0024.f.21; scan0024.j.16; scan0025.b.06; scan0025.b.15; scan0025.d.19; scan0027.m.14; scan0030.f.07; scan0032.a.02; scan0033.n.08; scan0035.j.07. 
Supplemental Table 2: Genes downexpressed in the ileum of piglets fed a low threonine diet (LT: $6.5 \mathrm{~g}$ threonine / kg diet) for two weeks.

\begin{tabular}{|c|c|c|c|c|c|}
\hline Clone & Contig & Gene & $\begin{array}{c}\text { Ratio } \\
\text { (LT/C) }\end{array}$ & $\begin{array}{l}\text { Swiss Prot tentative description } \\
\text { (highest similarity) }\end{array}$ & Biological process GO \\
\hline \multicolumn{6}{|c|}{ Cell cycle, proliferation, differentiation and death (11) } \\
\hline scan0026.h.21 & BQ599726 & BTG1 & 0.59 & BTG1 protein (B-cell translocation gene 1 protein) & $\begin{array}{l}\text { Negative regulation of cell growth ; Negative regulation of } \\
\text { cell proliferation }\end{array}$ \\
\hline scan0019.g.11 & BP164036 & PINX1 & 0.59 & Pin2-interacting protein X1 & Negative regulation of cell proliferation \\
\hline scan0003.h.05 & BX920295 & FOXC1 & 0.71 & Forkhead box protein C1 & Negative regulation of mitotic cell cycle \\
\hline scan0025.i.18 & AU296654 & POLL & 0.42 & DNA polymerase lambda (EC 2.7.7.7) (EC 4.2.99.-) & DNA repair \\
\hline scan0009.j.16 & BX919593 & Smg1 & 0.63 & Serine/threonine-protein kinase & DNA repair \\
\hline scan0011.k.16 & BX918925 & $T B C B$ & 0.60 & Tubulin-specific chaperone B & Nervous system development \\
\hline scac0043.e.12 & CB477020 & CDK5RAP3 & 0.67 & CDK5 regulatory subunit-associated protein 3 & Regulation of neuron differentiation \\
\hline scan0014.k.10 & CF791957 & NTRK2 & 0.61 & BDNF/NT-3 growth factors receptor (EC 2.7.10.1) & Nervous system development \\
\hline scan0020.b.08 & BX924367 & COL1A2 & 0.52 & Collagen alpha 2(I) chain precursor & Skeletal development \\
\hline scac0025.1.17 & BM484811 & COL9A2 & 0.63 & Collagen alpha 2(IX) chain precursor & Skeletal development \\
\hline scac0026.c.06 & CF178392 & DLL4 & 0.58 & Delta-like protein 4 (precursor) & Angiogenesis \\
\hline \multicolumn{6}{|c|}{ Transport (10) } \\
\hline scan0020.e.04 & CB287365 & $A P 3 D 1$ & 0.65 & Adapter-related protein complex 3 delta 1 subunit & Vesicle-mediated transport \\
\hline scac0033.k.01 & CB477797 & PCOLN3 & 0.57 & Charged multivesicular body protein $1 \mathrm{a}$ & Vesicle-mediated transport \\
\hline scan0032.i.13 & BQ604596 & GGA3 & 0.52 & ADP-ribosylation factor-binding protein GGA3 & Vesicle-mediated transport \\
\hline scan0036.g.11 & BQ600225 & VPS33B & 0.55 & Vacuolar protein sorting-associated protein 33B & Vesicle-mediated transport \\
\hline scan0004.p.03 & BX918993 & KIF2A & 0.55 & Kinesin-like protein KIF2 (Kinesin-2) & Microtubule-dependent intracellular transport \\
\hline scan0028.k.11 & CF179877 & TRAPPC5 & 0.59 & Trafficking protein particle complex subunit 5 & ER to Golgi vesicle-mediated transport \\
\hline scan0034.b.11 & BQ602404 & SEC63 & 0.61 & Translocation protein SEC63 homolog & Protein targeting to membrane ; Protein folding \\
\hline scac0033.k.04 & CF794880 & SYS1 & 0.62 & Protein SYS1 homolog & Protein transport \\
\hline scan0024.k.17 & BQ599032 & NUTF2 & 0.49 & Nuclear transport factor 2 & Protein transport \\
\hline scan0017.b.17 & BQ601586 & CDC42SE1 & 0.59 & CDC42 small effector protein 1 & Phagocytosis \\
\hline
\end{tabular}

\section{Cell communication, cell adhesion and cytoskeleton (1)}

\section{Regulation of transcription and RNA metabolism (13)}

\begin{tabular}{lllll}
\hline scan0035.b.12 & CF795871 & ZFP37 & 0.63 & Zinc finger protein 37 \\
scan0030.k.23 & BX916479 & ZNF429 & 0.49 & Zinc finger protein 429 \\
scan0010.k.05 & BX918916 & BAZ2A & 0.72 & Bromodomain adjacent to zinc finger domain 2A \\
scan0020.o.05 & CB480127 & PRMT5 & 0.67 & Protein arginine N-methyltransferase 5 (EC 2.1.1.-) \\
scac0030.d.09 & BX669065 & RBM9 & 0.62 & RNA-binding protein 9 \\
scaa0090.o.15 & BP439412 & SF1 & 0.72 & Splicing factor 1 \\
scac0025.i.06 & CF364599 & SFRS5 & 0.55 & Splicing factor, arginine/serine-rich 5
\end{tabular}

Cell communication

Regulation of transcription

Regulation of transcription

Chromatin remodelling

RNA splicing; Spliceosomal snRNP biogenesis

RNA splicing; Regulation of cell proliferation

RNA splicing ; Spliceosome assembly

RNA splicing ; mRNA splice site selection 
Online Supporting Material

\begin{tabular}{|c|c|c|c|c|c|}
\hline scaj0016.i.05 & CF361092 & SRRM1 & 0.60 & Serine/arginine repetitive matrix protein 1 & RNA splicing \\
\hline scac0033.1.01 & BM658825 & STRAP & 0.62 & Serine-threonine kinase receptor-associated protein & RNA splicing \\
\hline scan0005.o.02 & BX920377 & LSM2 & 0.71 & U6 snRNA-associated Sm-like protein LSm2 & RNA splicing \\
\hline scac0043.1.01 & BM190144 & HIST1H2BD & 0.74 & Histone H2B.b (H2B.1 B) & Nucleosome assembly \\
\hline scaa0004.m.17 & BE234098 & ELAC2 & 0.59 & Zinc phosphodiesterase ELAC protein 2 (EC 3.1.26.11) & tRNA processing \\
\hline scan0027.c.09 & CF176007 & EDC3 & 0.52 & Enhancer of mRNA-decapping protein 3 & mRNA degradation \\
\hline \multicolumn{6}{|c|}{ Cellular protein metabolism (10) } \\
\hline scan0031.d.16 & BQ600874 & PFDN2 & 0.45 & Prefoldin subunit 2 & Protein folding \\
\hline scan0022.i.02 & BX926209 & TOR1A & 0.49 & Torsin A precursor & Protein folding \\
\hline scac0033.l.16 & CB473763 & BAP1 & 0.78 & Ubiquitin carboxyl-terminal hydrolase BAP1 (EC 3.4.19.12) & $\begin{array}{l}\text { Ubiquitin-dependent protein catabolic process ; Negative } \\
\text { regulation of cell proliferation }\end{array}$ \\
\hline scan0020.b.19 & CF787985 & PSMB3 & 0.50 & Proteasome subunit beta type 3 (EC 3.4.25.1) & Ubiquitin-dependent protein catabolic process \\
\hline scac0029.d.19 & BM658988 & TRIP12 & 0.59 & Probable E3 ubiquitin-protein ligase TRIP12 (EC 6.3.2.-) & Protein ubiquitination \\
\hline scac0035.h.13 & CB477405 & $\mathrm{FBXO22}$ & 0.61 & F-box only protein 22 & Ubiquitin-dependent protein catabolic proces \\
\hline scan0038.j.06 & BQ604222 & BAT3 & 0.54 & Large proline-rich protein BAT3 & Protein modification process \\
\hline scac0039.b.02 & BM484008 & $U B Q L N 1$ & 0.67 & Ubiquilin-1 & Protein modification process \\
\hline scac0038.k.18 & CF181697 & GCN2 & 0.56 & $\begin{array}{l}\text { Eukaryotic translation initiation factor 2-alpha kinase } 4 \text { (EC } \\
\text { 2.7.11.1) }\end{array}$ & Regulation of translational initiation \\
\hline scan0020.d.09 & BQ605065 & EIF4EBP1 & 0.52 & Eukaryotic translation initiation factor 4A-binding protein 1 & Regulation of translational initiation \\
\hline \multicolumn{6}{|c|}{ Signal transduction (6) } \\
\hline scan0016.f.21 & CF795279 & PIK4CA & 0.55 & Phosphatidylinositol 4-kinase alpha (EC 2.7.1.67) & Signal Transduction \\
\hline scan0009.f.20 & AU296611 & PIP5K1C & 0.51 & $\begin{array}{l}\text { Phosphatidylinositol-4-phosphate 5-kinase type I gamma (EC } \\
\text { 2.7.1.68) }\end{array}$ & Signal transduction \\
\hline scan0006.j.01 & BQ603969 & IRF2 & 0.63 & Interferon regulatory factor 2 & Signal transduction \\
\hline scab0038.h.18 & AW486143 & МАРК 8 & 0.39 & Mitogen-activated protein kinase 8 (EC 2.7.1.37) & Signal transduction \\
\hline scan0039.f.24 & BX918476 & $B C R$ & 0.52 & Breakpoint cluster region protein (EC 2.7.1.-) & Signal transduction \\
\hline scag0006.b.06 & BQ601055 & JAK1 & 0.68 & Tyrosine-protein kinase JAK1 (EC 2.7.1.112) & Signal transduction \\
\hline \multicolumn{6}{|c|}{ Other biological process (7) } \\
\hline scan0037.n.06 & CB468944 & FABP5 & 0.51 & Fatty acid-binding protein, epidermal & Lipid metabolic process \\
\hline scan0020.o.14 & BQ597572 & GNPAT & 0.59 & Dihydroxyacetone phosphate acyltransferase (EC 2.3.1.42) & Fatty acid metabolic process \\
\hline scag0004.e.03 & BX665123 & CYB561 & 0.52 & Cytochrome b561 (Cytochrome b-561) & Generation of precursors metabolites and energy \\
\hline scac0028.c.01 & BX676542 & NMNAT1 & 0.52 & Nicotinamide mononucleotide adenylyltransferase 1 (EC 2.7.1.1) & NAD biosynthetic process \\
\hline scan0011.1.22 & CF366445 & NDST2 & 0.60 & Heparin sulfate N-deacetylase/N-sulfotransferase (EC 2.8.2.-) & Heparan sulphate proteoglycan biosynthetic process \\
\hline scan0020.e.14 & BM083159 & $M Y L K$ & 0.61 & $\begin{array}{l}\text { Myosin light chain kinase, smooth muscle and non-muscle } \\
\text { isozymes (EC 2.7.11.18) }\end{array}$ & Protein amino acid phosphorylation \\
\hline scan0018.1.09 & BM658572 & ARS2 & 0.44 & Arsenite-resistance protein 2 & Response to arsenic \\
\hline
\end{tabular}

Unknown biological process (21)

0.57 Hypothetical protein B0464.2 in chromosome III 
Online Supporting Material

\begin{tabular}{|c|c|c|c|c|}
\hline scac0034.n.21 & BQ602036 & EFEMP1 & 0.59 & EGF-containing fibulin-like extracellular matrix protein 1 \\
\hline scan0013.0.02 & CA781095 & KIAA1542 & 0.51 & RING and PHD-finger domain-containing protein KIAA1542 \\
\hline scan0018.b.18 & BP166641 & $T B C 1 D 13$ & 0.51 & TBC1 domain family member 13 \\
\hline scan0008.1.23 & BQ597366 & ARGLU1 & 0.55 & Arginine and glutamate-rich protein 1 \\
\hline scaa0090.k.14 & BM484348 & Pi4k2a & 0.59 & $\begin{array}{l}\text { Adult male spinal cord cDNA, RIKEN full-length enriched } \\
\text { library, clone:A330095A06 product:inferred: } 55 \text { kDa type II } \\
\text { phosphatidylinositol 4-kinase (Rattus norvegicus), full insert } \\
\text { sequence }\end{array}$ \\
\hline scan0013.b.22 & CB285603 & $B S D C 1$ & 0.63 & BSD domain-containing protein 1 \\
\hline scac0028.j.18 & BQ604045 & OBTP & 0.64 & Overexpressed breast tumor protein homolog \\
\hline scan0022.h.10 & CK454312 & MEGF9 & 0.47 & Multiple EGF-like-domain protein 5 precursor \\
\hline scag0007.b.08 & BQ604208 & Arl4c & 0.53 & ADP-ribosylation factor-like protein $4 \mathrm{C}$ \\
\hline scan0023.d.06 & CB469449 & ATP13A2 & 0.61 & Probable cation-transporting ATPase 13A2 (EC 3.6.3.-) \\
\hline scan0016.i.07 & CA779229 & KIAA0737 & 0.71 & Epidermal Langerhans cell protein LCP1 \\
\hline scac0027.a.17 & BX672648 & & 0.51 & Dpy-30-like protein \\
\hline scan0035.c.15 & BX671049 & $H I G D 2 A$ & 0.54 & HIG1 domain family member $2 \mathrm{~A}$ \\
\hline scac0038.1.24 & BQ602258 & MAPBPIP & 0.57 & Late endosomal/lysosomal Mp1 interacting protein \\
\hline scan0008.n.07 & CA778984 & $M R P L 46$ & 0.63 & $39 S$ ribosomal protein L46, mitochondrial precursor \\
\hline scac0036.h.23 & BQ600174 & MRPS23 & 0.68 & Mitochondrial ribosomal protein S23 (S23mt) \\
\hline scan0002.d.01 & BQ605112 & SGTA & 0.58 & Small glutamine-rich tetratricopeptide repeat-containing protein A \\
\hline scac0035.n.08 & BX670521 & FBXL12 & 0.57 & F-box/LRR-repeat protein 12 \\
\hline scan0027.n.16 & BX915058 & HELZ & 0.59 & Probable helicase with zinc-finger domain (EC 3.6.1.-) \\
\hline scac0035.p.20 & BQ601210 & FLOT1 & 0.67 & Flotillin-1 \\
\hline
\end{tabular}

Clones without informative annotation (31): scaa0016.c.10; scac0026.b.06; scac0026.c.15; scac0030.f.02; scac0031.d.15; scac0037.a.17; scac0043.e.19; scaj0009.c.15; scan0004.p.15; scan0005.l.13; scan0008.c.24; scan0008.d.05; scan0008.l.18; scan0012.h.19; scan0014.c.07; scan0014.j.07; scan0016.f.11; scan0016.f.14; scan0017.o.14; scan0018.k.20; scan0019.i.05; scan0021.1.22; scan0023.d.20; scan0023.p.09; scan0024.b.12; scan0026.g.18; scan0027.n.09; scan0030.j.05; scan0030.l.01; scan0037.a.24; scan0039.f.11. 